Portland State University

PDXScholar

1977

\title{
Program planning for community residents who have been released from mental institutions
}

Joseph D. Condon

Portland State University

Margaret Ann Drackert

Portland State University

Follow this and additional works at: https://pdxscholar.library.pdx.edu/open_access_etds

Part of the Social Welfare Commons, and the Social Work Commons Let us know how access to this document benefits you.

\section{Recommended Citation}

Condon, Joseph D. and Drackert, Margaret Ann, "Program planning for community residents who have been released from mental institutions" (1977). Dissertations and Theses. Paper 1925.

https://doi.org/10.15760/etd.1924

This Thesis is brought to you for free and open access. It has been accepted for inclusion in Dissertations and Theses by an authorized administrator of PDXScholar. Please contact us if we can make this document more accessible: pdxscholar@pdx.edu. 


\title{
PROGRAM PLANNING FOR COMMUNITY RESIDENTS WHO HAVE BEEN RELEASED FROM
} MENTAL INSTITUTIONS

\author{
by \\ JOSEPH D. CONDON \\ MARGARET ANN DRACKERT
}
A research practicum submitted in partial fulfillment of the requirements for the degree of

MASTERS in SOCIAL WORK

Portland State University

1977 


\section{ACKNOWLEDGMENTS}

The authors wish to thank a number of people who have been valuable to us in the completion of this project.

Peggy Harper, the third author of this project, started us on the right track and left us all too soon.

Pastor Rumsch was of great assistance with the needs assessment, and waited with patience for work he must have been sure was not forthcoming.

Our faculty advisors, Marian Ayerza and Nancy Koroloff, provided a great deal of support. Their information and criticism kept us working. Their kindness kept us motivated.

All the people whom we contacted in the community, service providers and clients, deserve our gratitude. Our ideas started with them.

And we wish to thank each other. The one without the other would never have attempted this project, much less completed it. 
TO THE OFFICE OF GRADUATE STUDIES AND RESEARCH:

These advisors approve the research practicum of

Joseph D. Condon and Margaret Ann Drackert presented June 1, 1977.

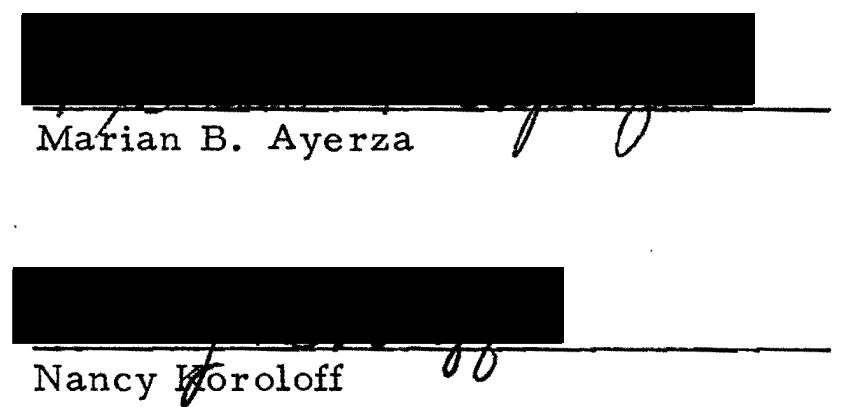


TABLE OF CONTENTS

PAGE

ACKNOWLEDGMENTS $\ldots \ldots \ldots \ldots \ldots \ldots \ldots \ldots \ldots \ldots$ iii

LIST OF TABLES $\ldots \ldots \ldots \ldots \ldots \ldots \ldots \ldots \ldots \ldots \ldots \ldots$ vi

CHAPTER

I INTRODUCTION $\ldots \ldots \ldots \ldots \ldots \ldots \ldots \ldots, 1$

II REVIEW OF THE LITERATURE ........ 3

Introduction

Major Studies

Recidivism and Symptomotology

Recidivism and Social Factors

Employment

Response to Aftercare

Extent of Social Participation

Summary

III

A NEEDS ASSESSMENT: METHODOLOGY,

FINDINGS, AND CONCLUSIONS .....

Methodology

Data Findings

Conclusions and Implications .......

Halfway Houses

Cooperative Apartments

Foster Homes and Ex-patient Clubs

Day Treatment Programs 
V A PROPOSAL FOR A DESINSTITUTIONAL-

IZATION PROGRAM $\ldots \ldots \ldots \ldots \ldots \ldots 70^{\circ}$

Introduction

Program Description

Problem Definition

Goals

Objectives

Strategies

Tasks

Linkages

Resources

Conclusion

APPENDIX A $\ldots \ldots \ldots \ldots \ldots \ldots \ldots \ldots \ldots \ldots \ldots \ldots \ldots$

A Selected Bibliography of Post-Hospital

Follow-up Studies of Mental Patients

APPENDIX B

89

A Selected Bibliography of Community-

Based Aftercare Programs

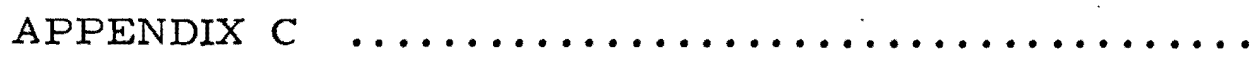

94

Research Instruments 


\section{LIST OF TABLES}

TABLE

PAGE

I A Rank Ordering of Means of Scores from

Service Providers Who Rated the Use

of Certain Residential Settings ...... . 36

II A Rank Ordering of Means of Scores from

Two Groups of Interviewees Who Rated

the Use of Training Opportunities .....

III A Rank Ordering of Means of Scores from

Two Groups of Interviewees Who Rated the Use

of Rehabilitation and Support Services ......

IV A Rank Ordering of Means of Scores from

Two Groups of Interviewees Who Rated

Program Methods $\ldots \ldots \ldots \ldots \ldots \ldots \ldots$ 


\section{CHAPTER I}

\section{INTRODUCTION}

Zion Lutheran Church in Portland has had contact with a number of neighborhood residents who have been released from mental institutions but who have had little community support. The Church has felt the need for some time to develop a residential program for former patients in the area they serve. The authors of this report agreed to conduct a needs assessment and to develop a program relative to the results of the assessment.

The overall method for this project was adapted from a planning model. Each chapter represents a distinct phase in the planning process. The outline for the project is as follows:

1. A search of the literature was conducted. Follow-up studies of the post-hospital experience of mental patients were examined in order to develop a perspective on the population with which this project is concerned.

2. A needs assessment identified the target population, attempted to determine what services they would use and how such services might best be delivered. The assessment was conducted in Northwest Portland because this is the general area 
which interests Zion Lutheran Church. It was designed to discern whether a residential program for released mental patients would be used in the area designated, and, if so, how such a program would best be formulated. However, it was also designed to allow respondents to express interest in other types of programs and services.

3. A number of program models were reviewed through a search of the literature. It included the types of programs that have recently been attempted. Each program type was then examined in terms of the feasibility of its development in Northwest Portland.

4. A program was suggested. Considering the goals and objectives of the project, the input from follow-up studies, the examination of program models, the results of the needs assessment, and other relevant factors, a type of program was proposed which best fit the needs of Northwest Portland and the resources of Zion Lutheran Church. The authors feel this project is timely. It corresponds to current trends in the field of mental health towards creating alternative community programs. This concept seeks to provide a broad range of services along a spectrum that fits peoples' needs at different times. And it seeks to place emphasis on community care care which is integrated and accepted within the community. 


\section{CHAPTER II}

\section{REVIEW OF THE LITERATURE}

\section{Introduction}

A major shift in the psychiatric hospital population occurred with the advent of psychotropic drug treatment in 1955. The effect was to reverse abruptly the trend toward higher inpatient census in mental institutions. The use of psychotropic drugs allowed larger numbers of formerly hospitalized patients to stay in the community. An awareness of the needs of this population was stimulated when Action for Mental Health was published by the Joint Commission on Mental Illness and Health in 1961. This publication was the beginning force in the move toward community mental health services as alternatives to hospitalization. Its authors said that hospitalization has effectively isolated the mentally ill and has thus fulfilled the function for society, "... to have out of the way persons whose behvior disturbs and offends them" (The Joint Commission on Mental Illness and Health, 1961, p. 11). In 1964 the move to de-emphasize hospitalization and to develop community alternatives took shape in the federal Community Mental Health Centers Act.

The result has been a burgeoning of community programs, of 
studies of the effects of those programs, and of interest in the posthospital adjustment of ex-patients. Some studies have developed from a psychological perspective which views intrapsychic patient characteristics at the root of post-hospital adjustment. Others have a social interactionist perspective which perceives adjustment as related to.role performance in the post-hospital environment. Most have found that, despite efforts to identify simple factors, there are many dimensions of an ex-patient's adjustment to community life. Paul (1969), in a study of treatment approaches, indicates that no specific treatment has been shown to have any long-term effect on discharge and community stay of chronic patients. In fact, hospital release without rehospitalization occurs only seven percent of the time. His conclusions are similar to many others: 1) The factors determining length of community stay reflect both individual behavior and the degree of distress imposed by significant others in the ex-patient's environment. 2) The degree of distress is modified by expectations, tolerance, and support offered to any particular. ex-patient.

Authors have criticized hospitals and community mental health centers for not preparing patients for their post-hospital experience. Kraft (1971) stated that too often hospital treatment is based upon expedience rather than the best interest of the client. Kirk and The rien (1975) felt that community mental health centers do not offer 
services for chronic patients but instead offer primary prevention, consultation, crisis intervention, and short-term outpatient care. Thus the development of community mental health centers has fostered four myths regarding community care. They are the myths of rehabilitation, reintegration, monetary savings, and continuity of care. Their criticism is that the segregation of psychiatric patients from the mainstream of society, as outlined by Action for Mental Health (1961), has now taken a different form.

Fairweather, Sanders, Maynard, and Cressler (1969) concur. Their focus is societal. They contend that the current cycle of mental patients, in and out of dependent living situations, is caused and reinforced by the stigmatized role patients are given and accept in society. Their solution necessitates major social change in which new and meaningful social statuses are established in order to allow ex-patients to grow to their full potential.

A sample of the complex of studies and their conclusions are represented here. Emphasis has been placed on those written since 1969 because studies which are dated before that time were conducted prior to the development of comprehensive community mental health programs. Presuming that the se community mental health programs have had some effect, earlier studies would have researched an expatient population which has recently changed in character. There are two types of studies of mental patients, as Paul (1969) indicates, 
prognostic studies and post-release follow-up studies. We have focused on the latter, since the former type refers only to stay in the hospital and its relevant factors. It was hoped that a more complete picture of the experience of former patients in the community and the factors associated with this experience could be derived from a review of follow-up studies. Five social factors repeatedly occur in follow-up studies. These are: recidivism, community tenure, post-hospital employment, response to aftercare, and the extent of social participation both within the family and in the community. Although theories constantly interconnect these factors, each article has been placed in a section which is most characteristic of its emphasis. First, however, four major studies will be described, each of which considers most or all of the above mentioned factors.

Major Studies

Freeman and Simmons (1963). In a thorough study that is perhaps the best known of this type, Freeman and Simmons (1963) attempt to measure the social consequences of release from the hospital for the ex-patient and his or her community. The study took place over a period of one year and was the third of a series by the authors. Freeman and Simmons conceptualize rehabilitation as a series of stages and attempt to study two of them. They are: 
1) The patient is able to stay in the community; and 2) the patient remains and functions, occupationally and socially, comparable to most adults in the community.

They found that rehabilitation cannot be viewed as a unidimensional phenomenon, that the two stages studied actually are independent dimensions. When the researchers examined rehospitalization, they found its risk was equally great throughout the year in which the study was conducted. It was most often initiated by a member of the ex-patient's family because he or she observed bizarre behavior, not because the ex-patient was unemployed or socially inept. When the researchers compared the work experience and the social participation of ex-patients who stayed in the community to the experiences and participation of those who did not, they found no significant difference.

Because the hypotheses of the study were sociological, the findings unexpectedly indicated that those who did not stay in the community manifested, numerically and qualitatively, more psychiatric symptoms than those who did stay. This finding complicated the application of role theory to analysis of deviant behavior.

Furthermore, neither the effects of past treatment, the type of treatment or diagnosis, the provision of follow-up treatment, nor drug therapy could be found significantly related to the stages of rehabilitation. However, duration of hospitalization, especially 
among fathers of families, was related to those stages.

The second unexpected result for the researchers was related. to tolerance of the ex-patient in his or her community. It was hypothesized that high tolerance would be a function of successful stay and that success would be characteristic of ex-patients living with parental families. It is here that the researchers separated the two stages of rehabilitation. While they found tolerance to be unrelated to rehospitalization, they found that lack of tolerance, or high expectations, was related to high instrumental performance in the community. In fact, relatives who not only had high expectations but also insisted upon them, tended to gain high performance from ex-patients. Thus ex-patients living in conjugal families were more likely to perform successfully, because they had higher status in their family and because there were higher expectations placed upon them. Contrary to the researchers' hypothesis, unmet high demands did not send the patient back to the hospital. Associated with this conclusion was the finding that a relative's feelings of stigma was unrelated to rehospitalization, but was related to performance. Perhaps such feelings of stigma affect expectations.

The authors could not find significant relationships between successful community tenure and any of the following: family type, duration of hospitalization, income, IQ score, anomie, or others' expectations. Therefore they hypothesize that the factors related to 
length of community tenure may be intrapsychic or that there may have been a methodological problem in this study. Finally, high expectations were seen to be associated with absence of symptomotology, and the two may be related.

Angrist, Lefton, Dinitz, and Psasmanick (1968). Angrist, et al, in Women in Treatment (1968) attempt to study both socialenvironmental and psychiatric variables as possible factors in community adjustment for a sample of female ex-patients. These variables are measured in relation to three possible outcomes after psychiatric hospitalization: 1) Ability to avoid readmission, 2) patient performance level, and 3) adequacy of patient performance compared to the performance of neighboring women.

The resultant theory was that manifestations of abnormal behavior in the family situation, an inability to live up to the family's expectations, and the family's unwillingness to have a deviant member at home will lead to rehospitalization. The degree of illness was not related to rehospitalization.

Somewhat differently than Freeman and Simmons, it was found that the significant others of patients who remained in the community held higher expectations than those of returnees. Those who were rehospitalized in this study were expected to perform only routine tasks and to engage in minimal social interaction. There 
was a relationship between psychiatric symptoms and performance. High and low performers, who were rehospitalized, were hospitalized for a psychotic episode. Whereas, low performers who remained in the community displayed chronic low level problems and symptoms.

Four factors were found to be related to post-hospital performance. First, psychiatric diagnosis and use of psychotropic drugs did affect performance. Second, social background variables such as marital status, type of family, composition of household and the ex-patient's role in it, all had consequences for performance. Like Freeman and Simmons, high performance was related to patients in conjugal families where other members were directly dependent upon them and where no role replacements were available. Third, lower social class tended to be related, although indirectly, to lower expectations and hence lower performance. Fourth, higher role expectations held both by the ex-patient for himself/herself and by him/her significant others were found in higher performance. Also a higher agreement between self-expectations and others' resulted in higher performance.

There were some intervening variables which affected the relationship of expectations and performance. These were: 1) Type of illness and diagnosis, 2) composition of patient's household, and 3) social class. For example, expectations of middle class women remained high despite performance whereas expectations of lower 
class women were based on their ability to perform expected tasks. In addition, there is no way to specify which of the two, role expectation or performance, is the independent or dependent variable. An "accommodation hypothesis" was proposed to explain the relationship between performance and expectations. Based upon selfexpectations, expectations of significant others, and the ability to perform, an accommodation process of interaction and mutual influence establishes actual performance.

The result of the study was that psychiatric symptoms alone could separate recidivists and community patients. The authors also state that the issues of psychiatric illness and inadequate role performance must be conceptualized as separate and distinct. Implications here are that once extreme symptoms are remitted or controlled the major therapeutic problem is to maintain adequate levels of interpersonal functioning so that the patient will remain a social participant. Community mental health programs need to understand when to raise or lower role expectations and to examine the adequacy of each phase of aftercare.

Michaux, Katz, Kurland, and Gansereit (1969). The course of psychological and social adjustment, or maladjustment, of former mental patients in the community was examined in this intensive longitudinal investigation. Each of 139 mental patients was interviewed 
monthly during the first year after their release to the community.

As in other studies, community adjustment was poorest among those living with parents and best among those living with a spouse. The authors concluded that parents generate a less supportive, interpersonal climate than spouses.

Time was an interesting factor in this study. Patients tended to learn how to handle their special social and environmental problems over the twelve months. During the same period, relatives grew more disappointed with former patients because their expectations were unrealistically high.

Discrimination between those who were rehospitalized and those who were not was related to two factors. They are: A patient's self-satisfaction and significant others' expectation and reporting of social performance. Those who were not rehospitalized were described as less anxious, busy people, satisfied with their free time activities. Those who were rehospitalized, on the other hand, were dependent and less active.

Four adjustment variables consistently proved important throughout the study: Degree of psychopathology, involvement in free time activities, patients' reporting of socially expected activities, and satisfaction of significant others with the ex-patients' performance of socially expected activities.

As a means to prevent rehospitalization the authors make 
the following recommendations:

1. That those who share daily living with the ex-patient receive mental health services.

2. That the patient have the opportunity to achieve social and recreational rewards.

3. That the mental health profession recognize the importance of an ex-patient's self-expectations, the expectations of others, and the discrepancy between expectations and performances.

4. That symptom reduction not be the emphasis of treatment. Heckel, Peery, and Reeves (1973). The Discharged Mental

Patient: A Five Year Statistical Survey is a follow-up study of formerly hospitalized mental patients. Former patients were sampled at given intervals during a five-year period. The results were then compared to a control group of college students who were sampled over the same period of time. The study was demographic and did not attempt to correlate factors. Those who returned to the hospital and those who did not were compared to each other and to the control group. The product is a somewhat generalized description of the "average" ex-patient.

For example, the study found married or separated expatients had better survival rates outside the hospital than did single or divorced ex-patients. Also, fathers returned to the hospital at a 
slightly higher rate than mothers. Those who returned to the hospital were more isolated and had more previous admissions than whose who did not return. The latter lived more with their parents, had slightly higher levels of financial attainment, and longer periods of employment.

At the completion of the study, 50.5 per cent of the ex-patient population had lived in the same place and forty-seven percent had not held jobs. (This includes those who resumed roles as housewives.) Also, there was movement from dependent behavior to a higher level of adjustment among those who remained in the community. Improvement of community adjustment was indicated by a decrease in daily contact with neighbors and an increase in contact with friends living at a distance.

In sum, these researchers found increased social sufficiency and competency in ex-patients during the three years. In fact, the behavior of these ex-patients became even more conforming and socially acceptable than the behavior of those in the control group.

Recidivism and Symptomotology

Factors which might discriminate between those patients who are rehospitalized and those who are not is the major topic of interest in five follow-up studies of patients released from psychiatric hospitals and community mental health centers. Arthur, Ellsworth, and 
Krocker (1968) reported that among their sample of 46 male veterans diagnosed as schizophrenics the degree of psychiatric symptomotology differentiated those who were rehospitalized from those who were not. A second finding was that instrumental role performance was unrelated to readmission. Arthur, et al, also found that the number and amount of previous hospitalizations and the attitudes of significant others toward the ex-patient are variables related to readmission.

With a sample of schizophrenics, Rosen, Klein, and Gittleman-Klein (1971) found three variables predictive of rehospitalization: "age at first psychiatric contact," "marital status," and "premorbid asocial adjustment." Of these, they concluded that "premorbid asocial adjustment" was an accurate indicator in 87.2 percent of the 81 cases sampled. Rosen, et al, therefore agree with Arthur, et al, that symptomotology is a significant variable related to rehospitalization. Gregory and Downie (1968) cited two variables which separate those who are readmitted from those who are not. These are the number of previous hospitalizations and the number of jobs held. They suggested that it is an individual's ability to assume responsibility for one's self and the chronicity and severity of symptoms which accounts for recidivism. Gregory and Downie, therefore, support the hypotheses of the first two studies. Rutledge and Binner (1970), when studying readmission to 
two community mental health centers, found that 85 percent of those patients who were readmitted were "therapeutic failures." That is, they were readmitted to a "more enveloping service," a service which was more institutionalized than what was rendered at their previous admission. Wessler and Iven (1970), researching the social characteristics of patients readmitted to a community mental health center, stated that the social variables of age, employment, and living situation we re not significant factors related to recidivism. In short, the five studies suggest that recidivism is related to symptomotology, not to demographic variables.

In a broad review of studies on recidivism Rosenblatt (1974) found only one variable which was a consistent predictor of recidivism, the number of previous admissions. His conclusions criticized the findings of studies such as the five above. He maintained that the re is a tendency in the psychiatric profession to search for determinants of rehospitalization in diagnostic and psychopathological terms. The result is a narrow focus that eliminates consideration of social processes. Erickson (1973) contended that the studies which use length of stay and recidivism rates as measures of success are unproductive because such measurement is based on the following assumption: Discharge from the hospital signifies successful completion of treatment and the lack of rehospitalization demonstrates the long term effectiveness of the treatment. Or the assumption may 
be that quick discharge and no readmission means more efficient, successful treatment. Erickson's position is that turnover and return rates are probably more effected by change in administrative procedures or by expectations of length of stay than by a breakthrough in treatment. Furthermore, the ease with which recidivism statistics are collected, tabulated, and used to evaluate costs makes them criteria serving accounting systems, not people.

\section{Recidivism and Social Factors}

Buell and Anthony (1973) investigated the demographic characteristics of an ex-patient population which might predict either posthospital employment or recidivism. Their research generated two significant findings. One, post-hospital employment is most efficiently predicted by the former patient's employment history, and likewise, recidivism is most efficiently predicted by the number of previous hospitalizations. Therefore, the best predictors of a former patient's future employment or hospitalization is the person's past experience. Secondly, post-hospital employment and recidivism were found to be two independent outcomes of psychiatric hospitalization; that is, these two outcomes have little effect upon each other. Buell and Anthony partially replicated their conclusions in a second study (Anthony and Buell, 1974). The factor of previous employment was repeatedly a significant predictor of post-hospital employment. 
However, past hospitalizations as predictors of recidivism were not consistent. In an earlier study, Kunce and Worley (1970) also arrived at conclusions similar to Buell and Anthony's original study. They identified rehospitalization and post-hospital employment as measurable outcomes and postulated that the number of prior hospitalizations was significantly related to rehospitalization.

Buell and Anthony offered the following statistical impressions which indicate the former patient's needs in the areas of employment and hospitalization.

$$
\begin{aligned}
& \text {.. the research... has repeatedly shown that } \\
& \text { one year after discharge, only } 25 \% \text { of the se } \\
& \text { patients are working full time and } 40 \% \text { have } \\
& \text { been rehospitalized at least once }(1973, \text { p. } 361) \text {. }
\end{aligned}
$$

As a final comment to their 1973 study, Buell and Anthony say that a description of a successfully employed ex-patient reflects the prejudices of the job market. The patient who has a stable employment history, a non-schizophrenic diagnosis, is married, is white, and possesses marketable job skills, is likely to be employed.

From 1967 to 1972, a time period which roughly corresponds to the Buell and Anthony studies, Lorei and Gurel designed a series of four studies (Lorei, 1967; Lorei and Gurel, 1967, 1972, 1973) which investigated predictors of post-hospital employment, recidivism, and community stay. They obtained similar results for schizophrenic and non-schizophrenic populations. The results support trends also 
noted by Buell and Anthony. Lorei and Gurel (1973) observed that the extent of recent employment is a more accurate predictor of employment than other demographic and background variables studied. Additionally, they suggested that

The lack of suitable roles in society for those with marginal vocational capabilities may be a much more serious barrier to productive activity by former patients than their mental status. (Lorei and Gurel, 1973, p. 430).

Through a factor analysis of ex-patients' individual characteristics, Lorei and Gúrel (1973) identified "chronicity/severity of the disorder" and "simple-mindedness" as factors predictive of employment. They also concluded that background or historical variables cannot predict readmission and that prediction of readmission may be based on situational determinants operating close to the point of readmission. In the same factor analysis study, Lorei and Gurel identified three factors predictive of stay in the community which they labeled "distress-alienation," "drinking/anti-social behavior," and "patient depreciation". by his or her significant others. Just as Buell and Anthony (1973) concluded that employment and recidivism are separate, Lorei (1967) concluded that patient attributes relevant to post-hospital employment do not overlap with those relevant to community stay.

A recent study by Fontana and Davis (1975) defined overall adjustment to the community during the first six months after 
hospitalization in terms of five variables: symptomotology, alcohol abuse, social involvement, employment, and organizational participation. These have been mentioned consistently throughout the literature. Their reported findings summarize tendencies found elsewhere in the literature in the works of Freeman and Simmons (1963), Buell and Anthony (1973, 1974), and Ellsworth, et al (1968). Generally, compared to the period before hospital admission, a decrease in symptomotology is maintained after hospitalization. Secondly, alcohol abuse decreases for.a short period of time and then resumes to the level of use before admission. Next, no difference in social involvement after hospital admission was reported. Adjustment to employment was greater before admission than six months after, and finally, organizational participation improved at a very slow rate. Thus, according to Fontana and Davis, time was necessary for the ex-patient to re-establish social contacts outside his/her family or friends. Also, patients and their significant others agreed that the criteria for overall adjustment are symptomotology and interpersonal contact between family and friends.

\section{$\underline{\text { Employment }}$}

Several studies have attempted to describe the employment experience of ex-patients. Olshansky, Grob, and Ekdahl (1960) examined four categories of ex-patients: re-employed; stably em- 
ployed; marginally employed; and unemployed. Their conclusions were: that the majority, after release, stayed at the same occupational level as before hospitalization; that they were not, as individuals, underemployed; that ex-patients had less difficulty adjusting to work roles than to social and family roles; and that there was no more job satisfaction or dissatisfaction than in the normal work force. They found some evidence of job discrimination. Griffiths (1973) developed a scale to compare work behavior of psychiatric patients in workshops and clerical units with norms appropriate in open industry. Components of the scale included task competence, attitude toward supervision and authority, relationships with other patients, work enthusiasm or motivation, and patient confidence and initiative. In a study of schizophrenics, Hall (1966) found it impossible to separate the effects of three factors: residual mental illness, marital status, and skill. A book by Simmons (1965) reported the detailed case histories of eight patients. He was critical of hospitals' lack of awareness of the individual's experience and needs and the manner in which patients were released into the community without follow-up.

\section{Response to Aftercare}

Each of the following three studies describes the chronic expatient's responses to treatment after hospitalization. Walker and 
his research associates (1973) discovered a negative correlation between improved production in psychiatric work rehabilitation and social behavior outside the treatment setting. They comment that ... the same aspects of a patient's behavior which facilitate a good response to treatment may militate against final community adjustment. (Walker, et al, 1973, p. 411).

George Wolkon (1970) concludes that the major characteristic of ex-patients which distinguishes participants from non-participants in a rehabilitation program is an "underlying theme of dependency." Additional characteristics of participants are that they perceived their families as wanting them to change, received government funds, were single, and were hospitalized for three months longer than nonparticipants. The conclusions of a study by Purvis and Miskimins (1970) are that ex-patients, active in follow-up group therapy, achieved high vocational and overall community adjustment, whereas active participants in individual the rapy achieved high vocational adjustment alone. These three studies suggest that there are varying responses to aftercare programs by ex-patients. However, it seems that ex-patients who are likely to conform to social pressures will also respond to aftercare treatment.

\section{Extent of Social Participation}

A number of studies have indicated that the amount of support which ex-patients receive in the community is related to the success 
of their adjustment. Blackman and Goldstein (1968) hypothesized a "reciprocation system" in which effects of stress may be reduced by drawing on the services and goods provided by others. Measey (1973) indicates that discharge to their home would be inappropriate for patients with difficult families. There would be more alienation and therefore less reciprocation in such homes, and those patients who are alienated are vulne rable to rehospitalization.

Others such as Davis, Pasamanik, and Dinitz (1972); Mannino and Shore (1974a); as well as Freeman and Simmons (1963) hypothesized that the support of others is related not only to community success, but also to others' high expectations. In two articles Mannino and Shore (1974a, 1974b) found that ex-patients with the most favorable outcomes were those who occupied high status positions in their families and who lived in families of procreation. In other words, success was related to the assumption of specific role expectations and responsibilities.

In a summary. of a large study of 1,045 patients over a fiveyear period, Miller (1967) reported that only 29 percent were not rehospitalized during that period. The author related failure to remain in the community with failure in role performance. But such failure was more likely to occur when roles were more diffuse, lower in status, or less demanding. Successful role performance also involved a psychological closeness to significant others, as in a 
conjugal family. This study also pointed out that positive roles were not easy for ex-patients because opportunity networks were not open to them. In that light the high rate of return to the hospital was not surprising.

Lyon (1974) and Stewart (1969), however, reported results in the opposite direction. Lyon found that home life with low demands and involvement with others was positively related to adjustment. However, his standard for change was symptomotology not role performance. Stewart found that expectations of relatives and of the patients themselves were higher than actual performance. He found social activity to be generally low among his entire population. A study by Davis, Pasamanik, and Dinitz (1972) was much broader based than the previous two. Their article, which is essentially a summary of a book-length study, Schizophrenics in the Community, by Pasamanik, Dinitz, and Scarpetti (1967), viewed ex-patients in three categories of treatment: 1) Home care with chemotherapy and with services of public health nursing, 2) home care with place of drug treatment, and 3) hospitalization followed by traditional aftercare services. Several scales, such as "domestic performance" and "social participation," were used to measure the categories. Also treatment interventions were measured to test their effect on each category. Little significant difference was found, five years after discharge; in social, psychological, vocational, or 
domestic functioning, regardless of aftercare approach.

Davis, et al (1972) found that ex-patients who were studied showed poorer friendship patterns and interpersonal abilities after hospitalization than before. Other studies also indicated that hospitalization had little or no effect upon community adjustment. Ellsworth, et al (1969), for example, said that hospitalization decreases symptoms but does not effect instrumental or role performance. A corollary finding is that adjustment is situational, that is, the welladjusted patient does not necessarily become a well-adjusted community resident. White (1974) also found pre-hospital and posthospital performance to be similar.

The dependency which hospitalization encourages may screen the population long before the patients are released to the community. Gralnich and Duncan (1961) hypothesized that one who enters a contract of institutionalization is a dependent person. A patient who admits this dependency increases his or her chances of release from the hospital. Hence, those released would tend toward dependent situations and toward rehospitalization.

A scale developed by Graham, et al, (1973) from the ratings of ex-patients by significant others confirms a tendency toward dependent behavior. The authors wished to find a way to evaluate an individual's functioning in the community through the use of psychologically interpretable dimensions. The factors they isolated could be 
seen as measures of dependency: belligerence, social conformity, withdrawal, fear-apprehension, disruption of communication, agitation-depression, and loss of control.

No single factor can be expected to explain an ex-patient's level of social participation. A survey by Spiegal (1972) of 725 former patients gives one a sense of the complexity, but little in the way of solutions. Bloom (1970) could only hypothesize, after finding that past history, current behavior at discharge, and family situation could not predict post-hospital success, that the key to successful community adjustment may be a number of unpredictable events which take place after hospitalization, such as changes within the family situation or los of job.

\section{Summary}

Although the studies discussed here were too varied to yield any consensus about ex-patients' characteristics or about their needs, certain factors a re consistently emphasized.

Perhaps the most significant of these, for purposes of programming, was the factor of recidivism and the conclusion that it is a separate issue from community performance. Repeatedly, studies demonstrated that rehospitalization was unrelated to performance on the job, with the family, or in the community. Recidivism, as many found, was apparently related to psychiatric factors, especially the 
manifestation of psychiatric symptoms.

Programs, then, should be developed with this distinction in mind. If the program goals are to reduce recidivism, then a program could be organized to help ex-patients manage psychiatric symptoms. On the other hand, if social functioning is to be increased, far different social and educational programs could be devised.

Many factors were related to community performance.

Several studies reported that high self-expectations and high expectations held by the ex-patients' significant others, led to high performance. This occurred particularly when ex-patients held high status family roles, usually in conjugal families where expectations for performance was high and tolerance of inappropriate role behavior was low.

Even those not living with any family members performed better in roles which were specific and demanding. Those living apart from their families who supported themselves financially performed better than those who were on public assistance.

But, as many point out, the post-hospital patient is a marginal person living outside society's opportunity network. Hence, Community-based aftercare programs face issues that reach far beyond the maladjustments of one or a group of ex-patients. 


\section{A NEEDS ASSESSMENT: METHODOLOGY, FINDINGS, AND CONCLUSIONS}

\section{Methodology}

Research Design. In order to gather information which would be considered when decisions were made about program development, a needs assessment was designed. The goals of this assessment were to locate the target population and to determine what services they would use and how such services might be delivered. This population includes those adults, twenty-one years old and over, who have been released from mental institutions. Such adults would live in licensed or unlicensed boarding homes or independent houeholds in the area of Portland served by Zion Lutheran Church. Persons who have drug or alcohol addiction, organic brain syndrome or retardation, or physical illness that requires nursing care would not be included in this target population.

The specific research questions were:

1. Will an additional residential facility, if provided, be used by the defined population?

2. What kinds of services do key informants think should be a 
part of a community-based program which serves this population?

3. What is the approximate size of the population? Is it large enough to support a program?

This study was prompted by several concerns. First, there was a need to learn more about the Northwest Portland Community and to experience the uniqueness of the neighborhood. The many contacts that were made as this study was conducted helped to gain the needed experience. Second, it was important not to duplicate existing efforts in the planning process. And, finally, little agreement was found in recent follow-up studies about what the needs of ex-patients are, which treatments are effective, or what defines community adjustment. A needs assessment, therefore, might clarify some of the unresolved issues found in the literature.

A key informant approach was used in this needs assessment. This approach is based on the assumption that a group of knowledgeable people can give information regarding the needs of another group of people in a specific community. The key informants included both consumers, who were members of the ex-patient population, as defined by this study, and professionals who served that population in occupational capacities. Throughout this report, these two groups of interviewees are referred to as "clients" and "service providers." 
The key informant approach to a needs assessment is a type of "action research." This means, first, that input gathered from leaders and consumers in the Northwest Portland Community is vital. Second, it means that the research accents that community by identifying local programs, by locating informants with a vested interest in Northwest Portland, and by finding potential users of a new program.

"Action Research" has several advantages. For example, key informants are readily accessible. And, based upon their experience, informants know what is acceptable to the community. Their responses and comments may then help the researchers distinguish the ideal from the real.

Development of the Research Instrument. A personal interview was selected as the research instrument for several reasons. When necessary, an interview would allow the researchers opportunities to clarify the questions asked, to probe for more information, and to acquaint themselves with existing services and key people in the community. Also, an interview would increase the degree of clarity concerning the defined population and the response rate of both service providers and clients.

A brief interview schedule was designed which contained seven structured items and one open-ended item. Two forms were 
devised, one for service providers and the other for clients, although items on both formis corresponded to one a nother. Introductory remarks to begin each interview were planned and were supplementary to the interview schedule.

Once developed, a pilot study of the interview schedule was conducted. Two service providers and one client who were by definition not direct service providers nor members of the target population were chosen and interviewed. The pilot resulted in minor revisions of wording. One item on the client form was also rewritten.

Sampling. The sampling was purposive, not random. Nineteen service providers were selected as key informants. These were people who provided direct service to the target population in Northwest Portland. These service providers were divided among five categories: Owner-managers of boarding homes and residential hotels, field workers of neighborhood agencies, ministers, caseworkers of the welfare department, and mental health professionals from mental health clinics and counseling centers. This division was necessary because it was assumed that service providers from a given discipline would tend to see a client situation in a given way and that a broad spectrum of opinion was desirable. Corollary to this is that different work experiences would also provide considerably 
different types of contact with the client population.

Six clients were selected to be interviewed as key informants. It was decided that three clients would be residents of Northwest Portland and that the remaining three would be members of $\mathrm{Zion}$ Lutheran Church. These church members may or may not reside in Northwest Portland. All six clients were part of the target population.

The purposive sampling of respondents was accomplished by soliciting names of key people, programs, and residential facilities from those already contacted. Generally the process began at Zion Lutheran Church where the researchers were referred to several ministers, thence to community agencies. Direct contacts were made with well known agencies such as the welfare department and neighborhood organizations, and these provided further referrals.

Data Collection. Data collection took place during September and October, 1976. Interviews were arranged by mailing letters of introduction to key informants. These were followed by a telephone call. Interviews took place in clients' homes and service providers' places of business. During the interview the researchers recorded responses, took notes, and answered interviewees' questions directly. In order not to bias the opinions of respondents, they were not informed that a residential program was being considered by 
Zion Lutheran Church. Two interviews were rejected as invalid, since the respondents indicated that they had no knowledge of the ta rget population.

Care was taken to protect the confidentiality of interviewees and their organizations in the following manner: Names were not attached to interview schedules, and the summary data only is reported in this study. Assurances of confidentiality were mentioned in the introductory letter and at the beginning of each interview.

Because the sample was a purposive one, only non-inferential statistics could be employed in data analysis. The data was summarized by tabulating frequencies, computing mean scores, and combining comments from open-ended questions into general patterns. The responses of service providers and clients were separated so that they could be compared. Comments were considered as anecdotal support or suggestions for program development. It must be remembered, too, that the figures obtained are gross estimates, not. precise measures.

\section{Data Findings}

All seventeen respondents to the service provider interview indicated that they did serve adults over twenty-one who had been released from mental hospitals. Not all those interviewed were located in the immediate area of Northwest Portland, but all seven- 
teen said that some of their clients lived in this neighborhood.

The interview schedule asked how many clients released from mental hospitals had been served by the service providers' organizations in the past year. Five service providers, four of them ministers, stated that they served an unknown number. Two of the ministers and a staff member of a neighborhood agency indicated that their organizations deliberately did not classify the individuals served in order to decrease the stigmatizing experiences of expatients and to encourage them to interact with other organization members. Two service providers did not respond. Ten service providers indicated that the number of clients served by their organizations amounted to an approximate total of 840 . These responses ranged from 20 to 292 individuals served.

In an attempt to discern whether there were persons residing in the community who were members of the ex-patient population as defined by the study, the respondents were asked what per cent of the total number served had a) drug or alcohol addiction, b) organic brain syndrome or retardation, or c) physical illness that requires nursing care. The percentage was then converted to numbers, with the result that roughly 190 were estimated to be within one of these categories. Alcohol or drug addiction was the largest with a total of nearly 150. Subtracting this number (190) from the total number served (840) gave a final total of approximately 650 individual client 
contacts. Thus an estimated 650 client contacts generally met the conditions which defined the ex-patient population studied.

Of the six clients interviewed, five were over twenty-one, five lived in Northwest Portland, and all six had been patients in mental hospitals. In addition, one client had been diagnosed as alcoholic. A second required nursing care. The rest of the clients did not have the specific problems listed above $(a, b, c)$.

Having been asked about themselves, clients were then asked about their acquaintances. The five clients who responded indicated that they did know other people who had been patients in a mental hospital. The total number of acquaintances approximated one hundred. Individual responses ranged from four to fifty. Asked about specific problems $(a, b, c)$ clients indicated they knew sixty people who were within the three categories. Therefore, they had approximately forty individual contacts who were members of the ex-patient population as defined by this study.

Interviewees were asked to provide information about the frequency of use of various types of residential settings by ex-patients in Northwest Portland. Service providers were given a choice of ranking residential settings according to the frequency of their use, with a ranking of one meaning "most frequently used" and a ranking of five meaning "least frequently used." General findings can be readily observed when the means of responses given to each category 
of residential settings by service providers are computed and compared. The raw data was first summarized through the use of frequency distributions. Means were then computed and placed in rank order. The order begins with the mean closest to a rating of one and continues through those closest to five, as presented in Table I.

\section{TABLE I}

\section{A RANK ORDERING OF MEANS OF SCORES* FROM SERVICE PROVIDERS ( $N=15)$ WHO RATED THE USE \\ OF CERTAIN RESIDENTIAL SETTINGS}

\begin{tabular}{lc}
\hline \multicolumn{1}{c}{ RESIDENTIAL SETTINGS } & MEAN OF SCORES \\
\hline Boarding Homes and Residential Hotels & 2.0 \\
Alone & 2.4 \\
Residential Care Facility & 2.6 \\
At home with Relatives other than Spouse & 3.8 \\
At home with Spouse & 4.1 \\
\hline
\end{tabular}

* A scale of 1 to 5 was employed. A scale score of 1 signified most frequently used and a score of 5 signified least frequently used.

It is important to recognize that fourteen of seventeen service providers responded to each part of this item on the interview schedule. One responded to some parts of the item, but not to all of it, and two did not. respond. These latter two stated that they knew only 
the former patients who resided in their facilities.

A general pattern of responses given by clients cannot be identified because three of six clients responded to this item. Clients who answered appeared to know more people who live alone, since all three clients ranked living alone as the first or second most frequently used residential setting.

In response to a further question regarding use of an additional residential facility, each of the seventeen service providers responded. The majority (14) stated that an additional residential facility would be used. However, five qualified their "yes" response with comments about the type of residential facility, the quality of the treatment program within the facility, and the eligibility of welfare recipients. Thus, there remained nine of seventeen service providers giving an unqualified "yes." Five clients who responded to this question reported that an additional residential facility would be used. One client did not respond.

Next, respondents were asked to rate training opportunities on a scale of one to four. A rating of one indicated that the respondent felt the training would be used very much by the population, whereas a rating of four indicated that it would not be used at all. Means were again drawn from the responses of both service providers and clients and ranked in order from one to four. The results are reported on Table II. 
TABLE II
A RANK ORDERING OF MEANS OF SCORES* FROM TWO GROUPS OF INTERVIEWEES WHO RATED THE USE OF TRAINING OPPORTUNITIES

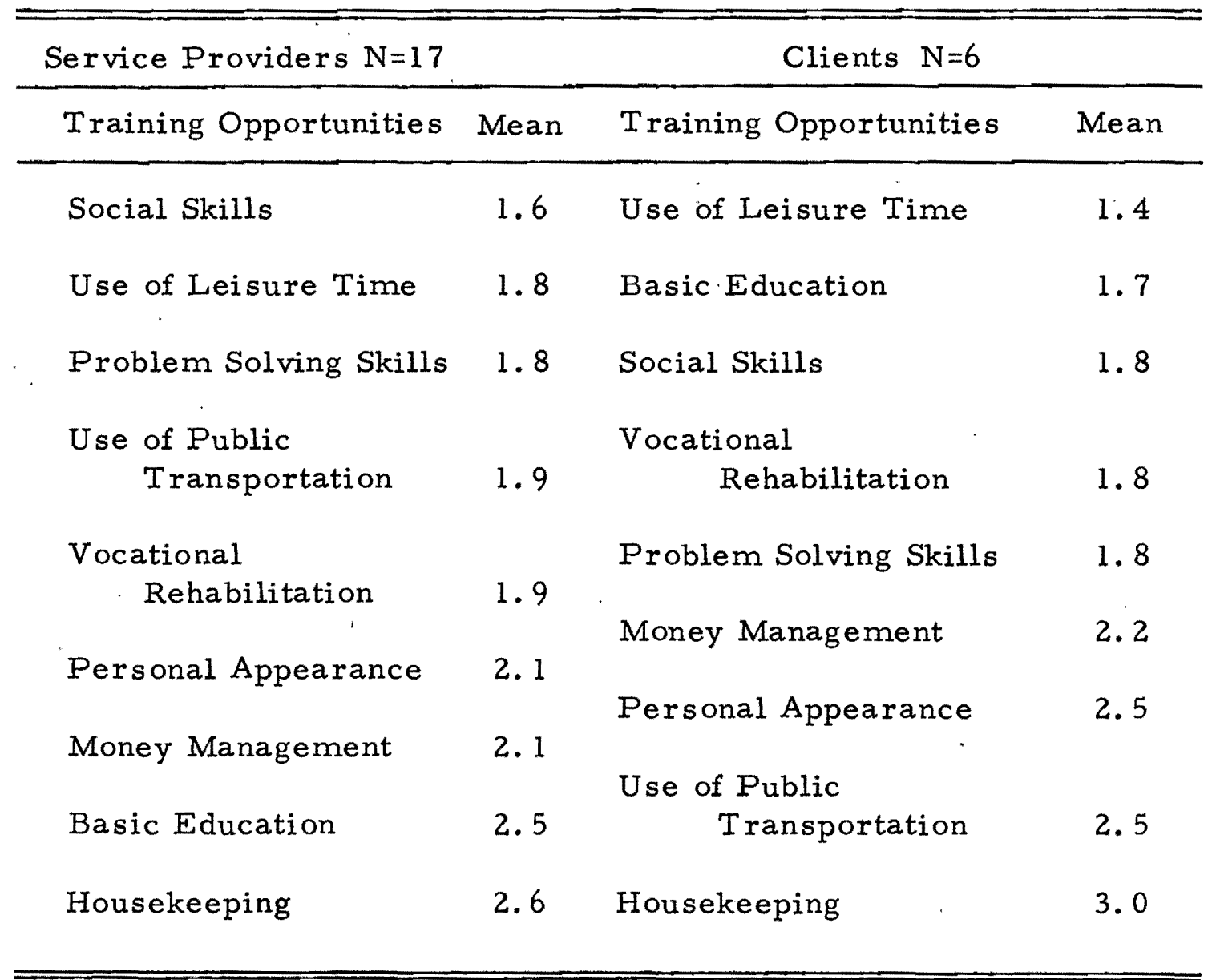

*A scale of 1 to 4 was employed. A scale score of 1 corresponded to "Would be very much used" and a score of 4 corresponded to "Would not be used at all."

Three categories rated by service providers may be noted. "Social Skills" had the mean closest to one (1.6). "Basic Education" was next to last in the rank order and "Housekeeping" was last, although the means of 2.5 and 2.6 , respectively, still were not close 
to an extreme possibility of a mean of four. Except for the last two items, the rest of the means are so close, and the sample is so small, that the remaining training opportunities will not be considered any further.

An "'other" category requested respondents to make further suggestions regarding training opportunities. Eight service providers did not respond. Those who did respond mentioned practical training in use of medication and in use of available resources such as public assistance in four instances. A second approach among those who responded was directed towards some training that would help clients to gain insight. Thus group work, activity therapy, and how to handle aggression and depression were among the suggestions. Clients, on the other hand, appeared to favor "Use of Leisure Time" (1.4) more than other choices, although a change in a single response with a sample of six could have placed several other categories close to it. "Use of Leisure Time" $(1.8)$ is close to the top of the rank ordering which was developed from the service providers' responses, but there also it is very close to means of several other responses. In contrast to the service providers' rank ordering, which placed it near the bottom of that list, "Basic Education"(1.7) is close to the top of the rank ordering established from client responses. Also, except for "Use of Leisure Time," clients stated that all the "Daily Living Skills," as they were called in the interview, 
were less useful than other training opportunities, with "Housekeeping" (3.0) least useful of all.

Three clients suggested additional training opportunities. All three indicated that some form of involvement, helping others, activities such as Church, or awareness of current events, was desirable.

Respondents were asked to rate the use of rehabilitation and support services with the same one to four rating system which was described above. The findings are presented in Table III. The top three categories in the rank ordering which was developed from service providers' responses were "Use of Trained Volunteers." (1.4). "Referrals to Community Agencies" (1.5) and "Individual Counseling" (1.6). "Family or Marriage Counseling" was at the bottom of this rank ordering with a mean of 2.7 .

An "Othe $r$ " category sought ideas for additional rehabilitation and support services. Again, service providers' suggestions tended to be practical. Transportation was seen as a need for this population by two service providers. Advocacy to help the client "Manipulate the Mental Health System" was also suggested by two. Two more service providers pointed out the need for community education about the ex-mental patient in order to alleviate the rejection of the ex-patient that often takes place in the community. One respondent suggested working with "natural systems" such as Bartenders, 


\section{TABLE III}

A RANK ORDERING OF MEANS OF SCORES* FROM

TWO GROUPS OF INTERVIEWEES WHO RATED

THE USE OF REHABILITATION AND

SUPPORT SERVICES

\begin{tabular}{|c|c|c|c|}
\hline \multicolumn{2}{|l|}{ Service Providers $N=17$} & \multicolumn{2}{|l|}{ Clients $N=6$} \\
\hline Services & Mean & Services & Mean \\
\hline Use of Trained Volunteers & 1.4 & Psychiatric Consultation & 1.0 \\
\hline $\begin{array}{c}\text { Referrals to Community } \\
\text { Agencies }\end{array}$ & 1.5 & Use of Trained Volunteers & 1.3 \\
\hline Individual Counseling & 1.6 & $\begin{array}{c}\text { Referrals to Community } \\
\text { Agencies }\end{array}$ & 1.3 \\
\hline Recreational Activities & 1.7 & Individual Counseling & 1.3 \\
\hline Clothes Closet & 1.8 & Clothes Closet & 1.3 \\
\hline Group Counseling & 1.8 & Supervised Group Living & 1.5 \\
\hline $\begin{array}{l}\text { 24-Hour Availability of } \\
\text { Professional Con- }\end{array}$ & & $\begin{array}{c}\text { 24-Hour Availability of } \\
\text { Professional }\end{array}$ & \\
\hline sultation & 1.9 & Consultation & 1.5 \\
\hline Supervised Group Living & 1.9 & Recreational Activities & 1.6 \\
\hline Psychiatric Consultation & 2.0 & Group Counseling & 1.8 \\
\hline Self-help Groups & 2.1 & Self-help Groups & 1.8 \\
\hline Legal Aid & 2.4 & Legal Aid & 1.8 \\
\hline Family or Marriage & & Family or Marriage & \\
\hline Counseling & 2.7 & Counseling & 2.4 \\
\hline
\end{tabular}

*A scale of 1 to 4 was employed. A scale score of 1 corresponded to "Would be very much used," and a score of 4 corresponded to "Would not be used at all." 
bus drivers, beauticians, and store owners in order to aid the expatient in his/her community adjustment.

In the only unanimous response to any item on the interview schedule clients all responded "Would be very much used" to the "Psychiatric Consultation" (1.0) category. In addition, there was more general agreement between service providers and clients in this item than in others. Clients also rated "Use of Trained Volunteers" (1.3), "Referrals to Community Agencies" (1.3), and "Individual Counseling" (1.3) high. They appear near the top of the rank ordering. In contrast, clients rated "Family or Marriage Counseling" (2.4) low and it appears at the bottom of the rank ordering. Only one client responded by suggesting job counseling as a rehabilitation service in the "Other" category.

Another item asked respondent to rate on a scale of one to four whether ten different methods would be excellent, good, fair, or poor means of offering services to the ex-patient population. The findings are summarized in Table IV.

The seventeen service providers in the sample tended to respond that "Outpatient Clinical Services" (1.3), "Day Treatment Program" (1.6), "On-the-job Training" (1.8) and a "Short-term Residential Facility" (1.9) were excellent or good program methods. Mean responses fell below 2.0 in all other cases except one, "Community Service Center." Here the mean was 1.9 , but it could 
TABLE IV

A RANK ORDERING OF MEANS OF SCORES* FROM TWO GROUPS OF INTERVIEWEES WHO RATED PROGRAM METHODS

\begin{tabular}{|c|c|c|c|}
\hline Service Providers $N=17$ & & Clients $N=6$ & \\
\hline Services & Mean & Services & Mean \\
\hline Outpatient Clinical Service & 1.3 & $\begin{array}{c}\text { Short-term Residential } \\
\text { Facility }\end{array}$ & 1.2 \\
\hline Day Treatment Program & 1.6 & Community Service Center & 1.3 \\
\hline On-the-job Training & 1.8 & Day Treatment Program & 1.4 \\
\hline $\begin{array}{c}\text { Short-term Residential } \\
\text { Facility }\end{array}$ & 1.9 & Sheltered Workshop & 1.7 \\
\hline Community Service Center & 1.9 & On-the-job Training & 1.7 \\
\hline $\begin{array}{c}\text { "Big Brother/Big Si.ster" } \\
\text { Program }\end{array}$ & 2.1 & $\begin{array}{l}\text { Foster Homes } \\
\text { Long-term Residential }\end{array}$ & 1.8 \\
\hline $\begin{array}{c}\text { Apartment Co-op } \\
\text { Program }\end{array}$ & 2.3 & Facility & 1.8 \\
\hline Sheltered Workohon: & & Apartment Co-op Program & 2.0 \\
\hline Sheltered Workshop & 2.3 & Outpatient Clinical Service & 2.0 \\
\hline $\begin{array}{c}\text { Long-term Residential } \\
\text { Facility }\end{array}$ & 2.5 & $\begin{array}{c}\text { "Big Brother/Big Sister" } \\
\text { Program }\end{array}$ & 2.5 \\
\hline Foster Homes & 2.7 & . & \\
\hline
\end{tabular}

*A scale of 1 to 4 was employed, 1 corresponded to "Excellent," 2 to "Good," 3 to "Fair," and 4 to "Poor."

be excluded as a priority of service providers because three failed to respond to this category. In the "Other" category associated with 
this item, fourteen of seventeen service providers offered no suggestions. The remaining three suggested programs such as foster homes with highly trained foster parents, an overnight dropin center with emergency services, and a communal block within a neighborhood of group homes and family residences.

Clients tended to report that a "Short-term Residential Facility" (1.2), a "Community Service Center" (1.3), and a "Day Treatment Program" (1.4) were excellent or good program methods. Clients gave no specific suggestions regarding program models.

When comparing the service providers' ratings of program models to clients' ratings, a discrepancy regarding "Outpatient Clinical Services" becomes apparent. Service providers rate this as their first choice with a mean of 1.3 , whereas clients rate outpatient services as their next to last choice with a mean of 2.0 . In the case of a "Short-term Residential Facility," service providers and clients rated it in the upper half of program methods. The remaining residential options such as "Foster Homes," a "Long-term Residential Facility," and an "Apartment Co-op Program," were rated in the lower half.

At the end of: the interview respondents were asked what they would do to help those persons making the transition from hospital to community. Sixteen service providers responded and one did not. At least three or more service providers made the following 
suggestions: Quality housing alternatives (7), some type of supportive counseling (6), provision of post-hospital aftercare services (5), mental health and welfare systems advocacy (4), and adequate living situations (3). In addition, two service providers mentioned that a group of neighborhood churches and organizations were considering buying a piece of property in the community and converting it into a multi-service center.

All six clients responded. In general, they reported that the provision of some type of leisure time activities (6) would be beneficial. One client mentioned that professional counseling with patients' relatives and friends regarding mental illness might be helpful.

Neither service providers nor clients mentioned employment, vocational training, or anything related to vocational interests in response to this item.

\section{CONCLUSIONS AND IMPLICATIONS}

In this section conclusions will first be discussed in terms of the three specific research questions proposed by this needs assessment. Secondly, implications relevant to program development will be presented.

Since the large majority of service providers and clients said that an additional residential facility would be used by the defined 
population, it would seem that the conclusions to the first research question would be definitely in favor of a new residential facility. However, support for a new residential facility is lessened because, of the fourteen positive responses in favor of a residential facility, five responses were qualified. Usually the respondent who was qualifying stipulated that such a facility should provide quality service and treatment. Thus it can be concluded that some service providers feel that a quality residential facility would be an important addition to the neighborhood, but not a priority. The need for adequate living arrangements is emphasized by the ten respondents. who said, in response to the open-ended item, that quality housing and adequate living situations would be among provisions they would offer, if they could. A second conclusion, according to service providers who responded, is that the population in question frequently uses room and board resources and infrequently resides with their families. Therefore, and again according to service providers, ex-patients in Northwest Portland are already living in residential settings, although in some cases the adequacy of their living situation is questionable.

Clients were:reluctant to rank the frequency of use of various living arrangements by the ex-patient population. Two clients commented that they had not had much exposure to various types of alternative residential settings apart from their particular 
living situation.

The interview also sought respondents' opinions of other programs. The only residential program rated in the upper half of program methods was short-term residential care. All other types of residential programs were rated low by both service providers and clients. Thus again a residential program is favored but with strict qualifications.

The question, then, is what programs do service providers and clients consider to have priority? The answer to this is not clear from the data. Service providers clearly saw outpatient clinical services as valuable to the population. But a day treatment program was the only method, other than short-term residential care, rated generally high by both service providers and clients.

It should be recalled that the original purpose of this study was to discern the needs for an additional residential facility in Northwest Portland, and for services that might be included in such a facility. The research tended to favor establishing a residential facility. But a definite conclusion that key informants favored a residential facility cannot be made, since the responses were not as clear as might be expected.

One implication of the results is that the researchers have begun to look at the study in a different light. It was felt that the tendency to use boarding homes and residential hotels as living 
situations, as well as the tendency not to use services such as marital and family counseling, was indicative of the neighborhood. A good percentage of ex-patients living in Northwest Portland already live in a residential facility of one kind or another. It appears that another facility would only add to what is already there.

There are also two additional implications. First, another residential program might serve only a very small part of the expatient population. Second, any program designed for the Northwest neighborhood could expect to be dealing with a high risk population. As incidated by the literature, ex-patients who live apart from families tend to be less successful in length of community stay, employment, and social participation than those who live with relatives, especially spouses.

Three other factors also lead the researchers to conclude that a residential program may not be feasible at this time. First, the City of Portland has not been licensing Residential Care Facilities since July, 1976. A new city-wide plan for specialized group homes which provide treatment services is now being developed. Given this political situation regarding the distribution of Residential Care Facilities throughout Portland, there is question of neighborhood acceptance of another residential facility. Second, residential programs do exist for the population in Northwest Portland. Excluding a short-term residential facility the other most often mentioned 
program in the study, day treatment, is not available in this part of the city. Finally, the re are plans to develop a multi-service center in Northwest Portland now being discussed by neighborhood agencies. An aftercare program other than residential could fit well with the se plans.

A conclusion to the second research question is that leisure time activities, training in social skills, use of trained volunteers, referrals to community agencies, individual counseling, and psychiatric consultation are services that key informants recommended for community residents who have been released from mental institutions. Three service providers also favored training opportunities in the use of medication. Clients strongly recommended leisure time activities, and data findings consistently support this conclusion. For example, clients suggested that some type of leisure time activities would be beneficial and that a community service center in which recreational and social activities might take place was an approved program model. Finally, three clients suggested that a greater degree of social involvement would be useful. Service providers tended to agree with clients, although their support of leisure time activities was not as consistent. However, training in social skills and in the use of leisure time were rated higher than any other training opportunity by service providers. Additional support for this conclusion is evident in two suggestions 
concerning the provision of activity therapy also made by service providers.

Service providers rated the use of trained volunteers, referrals to community agencies, and individual counseling generally higher than other types of rehabilitation and support services. Because the range of means obtained was small and thus did not vary one from another, strong support for the selection of these three services instead of others was not apparent. Clients unanimously approved of psychiatric consultation as a useful service. After this choice, however, their priorities for services matched the top three priorities of service providers. Hence, there is general support for the services mentioned above.

According to service providers the resources of the mental health and/or welfare systems are valuable yet often inaccessible to ex-psychiatric patients. This conclusion is based on eight comments by service providers concerning criticisms of the mental health and welfare service delivery systems and concerning advocacy for its users. On the other hand, both clients and service providers favored referrals to community agencies.

Service providers and clients rated family and marriage counseling lower than any other rehabilitation or support service. Similarly daily living skills, especially housekeeping, we re generally rated as less useful than other training opportunities. Therefore, 
clients and service providers in Northwest Portland do not favor family and marriage counseling nor training in daily living skills for the ex-patient population.

These recommendations of key informants have implications for use in program development. One implication is that the kinds of services recognized as important do not necessarily depend upon a residential setting. These services could be delivered through a variety of program models. In fact, services such as leisure time activities, the effective use of volunteers, and referrals to community agencies, may be best delivered outside a protective residential facility rather than inside it. It seems that the existing boarding homes, group homes, and other types of residential facilities in the neighborhood of Northwest Portland are not providing the quality or quantity of services desired by key informants of the same locale. The researchers gathered a great deal of data, comments, and recommendations about what could be done to improve services especially in the areas of use of leisure time, use of medication, and use of community resources. Another implication is that psychiatric consultation or some link to the psychiatric profession is an important program consideration. Furthermore, volunteers are acceptable within the neighborhood studied and are perceived as a useful program component.

The conclusion to the third research question is that a 
sufficient number of ex-psychiatric patients does exist in Northwest Portland to support a program, especially a small one, even though an accurate count of the defined population could not be attained by this study. All key informants indicated that they were aware of the population as defined by the study. The likelihood that there is considerable duplication of numbers in the figures reported does not negate the awareness of these key informants. The few that admit they deliberately do not keep track of this population actually confirm this point. Moreover, few service providers kept statistics which defined the population and few kept accurate service counts. Thus, an accurate count of the target population could not be attained anywhere. The gross figures reported are the results of this research effort.

Several implications arise from the conclusion that the population studied was difficult to locate. First, if they cannot be found, how can effective aftercare methods be developed and tested?

Second, how can factors mentioned in the literature, such as rates of recidivism, socialization, community adjustment and employability, be measured and thus yield useful information for program development?

All these questions come to bear on a new program which is attempting to be accountable. They will have to be considered when planning for such a program. 


\section{PROGRAM FEASIBILITY}

This chapter will review a variety of community-based aftercare programs that are reported in the mental health literature. The purpose of the chapter is to answer the question of feasibility. What kinds of programs can be developed which will best serve former psychiatric patients who now reside in the neighborhood of Northwest Portland? Each type of program reviewed in this chapter will be analyzed in terms of feasibility. A decision regarding feasibility of a proposed program will address the issues of the program's clientele, its treatment philosophy, its mode of service, location, size, economics, acceptance by the community, and its effectiveness.

\section{Halfway Houses}

Generally speaking, halfway houses are residences for mental patients who no longer need to remain hospitalized, but are, as yet, unable to establish independent residences in the community (Wechsler, 1960). Most require that the client be able to function at some acceptable level in keeping personal belongings in order, handling money, and controlling destructive or antisocial behavior 
(Richmond, 1968, 1969; Hersen, 1969; and Landy, 1965). Some halfway houses require that the client be employed or moving towards employment (Hersen, 1969; Gill, 1967; Gumrukcu, 1968; Mikels and Gumrukcu, 1963b). Clientele, therefore, are screened according to their ability to live in the semi-independent atmosphere of a halfway house. Other criteria also may be taken into consideration. For example, Sheaver (1969) points out that those with long-term illnesses have more to gain in a halfway house situation than do those with short-term difficulties.

Expected length of stay varies with the treatment philosophy. Some halfway houses set no specific time limits in order to avoid separation anxieties (Landy, 1965; Easton, 1974). Programs for chronic patients tend to set longer time limits, as much as five years (Huessy, 1969b). The average length of stay, however, is approximately one year (Mikels and Gumrukcu, 1963; Wechsler, $1960)$.

The majority of halfway house programs described in the literature are characterized by a "high expectations" approach (Richmond, 1968, 1969; Landy, 1965; Wilder, 1968; Jansen, 1970; Easton, 1974). The emphasis of such an approach is performance. Residents are taught social skills and given responsibility within a protective structure (Richmond, 1968, 1969; Rothwell, 1966). Raush and Raush (1968) refer to "high expectations" as a "sociological" 
approach in which the program itself is designed to play an active role in corrective and restorative processes. According to the sociological model, rehabilitation occurs through social adaptation. Raush and Raush contrast it to a "medical" or "nurturing" model which contends that a patient needs time to recuperate from an illness. The house in this case provides a supportive or neutral environment in which recuperation may take place. It recognizes the "mental illness" of an individual and he/she is treated accordingly. Consequently the "sick" label that one acquires by having been hospitalized is encouraged even after hospitalization (Easton, 1974; Richmond, 1969).

Yet halfway houses have been developed to facilitate an expatient's transition from hospital to community by delaying briefly a resident's constant exposure to the pressures of community living (Landy, 1965; Shearer, 1969). Different authors describe in different ways what occurs during this brief delay. Sharp (1964) and Landy (1965) characterize the halfway house's function as dealing with role confusion. The client learns and relearns social roles in order to shed the patient role. Easton (1974) takes a more existential approach by defining "optimal achievement of self-realization" as the halfway house's function.

Whatever the:goals and functions of halfway houses may be, there is general agreement in the literature that a house should be 
therapeutic and should provide an optimum environment for the clients to test and to realize their potentialities for health (Reik, 1953; Goveia, 1965). Others, such as Gumrukcu (1968) and Rothwell (1963) feel that treatment is best accomplished in a homelike atmosphere.

There have been few attempts to standardize the type of treatment which should occur within halfway houses (Wechsler, 1960). The result is that halfway houses are isolated from each other and need coordination (Rog and Raush, 1975; Jansen, 1970). However, Huessy $(1969 a, 1969 b)$ points out that a variety of halfway houses / programs, coordinated to provide service options to meet the needs of ex-patients at various levels, can be beneficial. But coordination is a problem. Each halfway house is influenced to provide services which fit its unique situation by factors such as its sponsorship, its professional orientation, and the diagnostic categories of its clients (Gumrukcu, 1968).

There is some general agreement about treatment methods however. For example, often few written rules exist in a program (Wechsler, 1960; Mikels and Gumrukcu, 1963; Rothwell, 1966; Gill, 1963). But even those programs with few rules plan daily schedules and specific events which include considerable structure (Easton, 1974; Weiss, 1969; Huessy, 1969b; Landy, 1965).

Staffing of halfway houses varies. Most employ para- 
professional staff to live in and to fulfill supervisory and administrative responsibilities. Some supplement paraprofessional staff with full-time professional staff (Rog and Raush, 1975). Others have professionals on call or as regularly scheduled consultants (Raush and Raush, 1968). Some halfway houses have "non-referred" residents, that is, residents who are not former mental patients. These residents function as role models and as "normalizing" influences within the houses (Gumrukcu, 1965, 1968; Gi11, 1967).

Halfway houses are generally established in existing housing in the community. However, their location is one of the larger problems of halfway houses. Problems of city, county, and state program regulation and building standards can seriously hamper development of programs (Budson, 1975).

Once a program has a house, there is a further problem of keeping the house in adequate repair. As Easton (1974) indicates, the constant need for repair can be a source of anxiety. The choice of a house, its location, and its repair may have as much to do with what its supporters can afford as with therapeutic considerations. There are differences of opinion about the most effective size of a halfway house program. Rothwell (1963) feels that smaller size permits a home atmosphere. Easton (1974) opts for larger programs for two reasons. First, there is greater opportunity for finding friends in the larger house. Secondly, a demand for close 
relationships may exist in the smallex houses and they could consequently be excessively stimulating, ego destructive, and disorganizing for the ex-patient.

Halfway houses also have problems of acceptance by the community. Jansen (1970) feels that the public is not ready to accept the community care concept and that development of a halfway house program should, therefore, include community education. Goveia (1965) points out that the social consequences of having been ill are large and that a community's attitude towards former patients is often transferred to the halfway house itself.

In the continuum of mental health care delivery systems halfway houses do appear to have a viable role. A former mental patient can benefit from the supportive services which a halfway house provides. The total environment of residential care could have an encompassing effect on the patient who is having a difficult time adjusting to community life. In order to realize their potential, however, halfway houses need to be standardized and regulated to insure something more than the low grade custodial care that some inferior halfway houses provide (Rog and Raush, 1975).

Even with the best of programs, halfway houses have some built-in problems. Rothwell (1963) mentions three areas: They are able to serve only those who can maintain a surface level of behavior; roles in a halfway house are not as clear as in a hospital; and it is 
very difficult to predict the effect of a program upon any incoming resident.

Since the authors began with the concept that a halfway house would be the type of program to be developed in this project, considerable time and effort has been given to an investigation of this type of program. However, these programs entail large economic problems. Purchase or lease of urban property plus its upkeep and repair is expensive. So also are the salaries that must be paid to professional and paraprofessional staff. Halfway house developers also need to consider city and state regulations. As indicated in the needs assessment, regulations in Northwest Portland are now prơhibitive. The community is not receptive to new residential facilities. Therefore, a decision was made by these authors that a halfway house would not be the most feasible program to develop. There are too many' untested factors and too many hidden expenses to recommend such a program for this project.

\section{Cooperative Apartments}

The concept of cooperative apartments as one type of a residential aftercare program was derived from the halfway house. movement. The first cooperative apartment, established in New York City in 1964, was an adjunct to Fountain House. Cooperative apartments have been developed in conjunction with state hospitals, 
halfway houses, and mental health associations primarily for the chronic hospitalized patient (Hodgman and Stein, 1966; Chien and Cole, 1973; Kresky, et al, 1976; and Richmond, 1976). Generally, a small group of ex-psychiatric patients share an apartment located in a residential neighborhood as their means of achieving semiindependent living in the community. Minimal supervision is usually provided daily by non-professionals such as landlords or neighbors, and weekly by mental health professionals.

The treatment philosophy which is discussed in the literature on cooperative apartments is the same as the treatment philosophy of halfway houses and day treatment centers. The effects of longterm hospitalization, rehospitalization, social and vocational rehabilitation, and community adjustment are familiar and frequently mentioned parts of the treatment philosophy (Hodgman and Stein, 1966; Chien and Cole, 1973; Kresky, et al, 1976; and Richmond, 1969). The innovation of this type of program is that it is communitybased rather than institution-based.

The size of an apartment cooperative program is adapable. It can be very small and consist of one apartment or it can be a large number of apartments in several neighborhoods. Chien and Cole (1973) compared the annual maintenance costs per patient of institution-based and community-based treatment facilities and concluded that the cost of a person living in a cooperative apartment 
was less than placements in state hospitals, nursing homes, traditional halfway houses, foster family care, and boarding homes. Richmond (1969) and Kresky, et al, (1976) also emphasize the low cost of this type of program. Besides being less costly, cooperative apartments were also found to be more acceptable in residential neighborhoods than were halfway houses. Finally, an evaluation of the Boston State Hospital cooperative apartment program demonstrated that the venture was beneficial in the sense that residents, landlords, and hospital staff were highly satisfied with the program (Chien and Cole, 1973). However, Kresky, et al, (1976), speaking from their experience at Woodley House in Washington, D. C., point out two problems in the operation of cooperative apartments. First, residents were delinquent in the payment of their rent and other living expenses, and second, they displayed behavior that was difficult to manage within the context of a cooperative living situation.

At first glance a cooperative apartment program seems a feasible option. It is based on a treatment philosophy of individual independence and responsibility. The mode of service is flexible enough to meet the needs of residents at many different levels. It is a setting that is less institutional than a halfway house. This type of program can be small, inexpensive; and can use the services of volunteers. Although not a favorite program model among 
respondents to the Needs Assessment, an apartment cooperative would most likely be acceptable within the neighborhood of Northwest Portland. Despite these advantages, apartment cooperative programs are limited because they usually serve a small number of people who need minimal social support. A need for minimal social support is not characteristic of the ex-mental patients who are potential clients of the proposed program.

Foster Homes and Ex-patient Clubs

Among references in the literature to many types of aftercare programs, foster home programs which house psychiatric patients in the community (Murphy and Engelsman, 1976; Cunningham, et al, 1969) and ex-patient clubs are mentioned. Both program concepts, developed in the early 1950s, are older ones. They marked the beginning of the trend towards community mental health programs. Foster homes have been criticized because they generally do not facilitate an improvement in an ex-patient's social functioning (Murphy and Engelsman, 1976). Furthermore, Wechsler (1961) criticizes ex-patient clubs because they, as yet, have not been successful in recruiting or retaining membership. One reason is the social stigma attached to these clubs. Another is the difficulty that club members have relinquishing the role of mental patient. Both foster homes and ex-patient clubs are inexpensive and 
acceptable to the community, although perhaps not to the ex-patient. They both can vary in size and location. However, it is the conclusion of the authors that these programs are not presently feasible because they reinforce marginal roles for ex-patients in the community and therefore do not meet the extensive emotional, vocational, social, or recreational needs of persons who have histories of long-term institutionalization.

$\underline{\text { Day Treatment Programs }}$

Another type of aftercare program that has become increasingly popular during the last decade is the day treatment center. Such centers attempt to improve the emotional functioning of clients while they are living outside of a hospital setting. Several authors on day treatment (Meltzoff and Blumenthal, 1966; Glasscote, 1969; and Gross, 1971) concur that the clientele of day treatment centers are typically chronic psychiatric patients who are unemployed, unable to live independently, and who need frequent contact with mental health services. Glasscote (1969) refines the description of the clientele by adding that they have poor employment records, poor instrumental skills, and poor family relationships. He further suggests that persons who are suicidal, potentially harmful to others, unable to travel to a center, or heavily medicated may not be appropriate candidates for day treatment services. 
Meltzoff and Blumenthal (1966), Glasscote (1969), Gross (1971), and Glaser (1969) agree that day programs are based on a philosophy of treatment which maintains that rehabilitation from long-term custodial care and integration into the mainstream of society is a possibility for persons who have been labeled mentally ill. Day treatment programs are perceived as alternatives to inpatient hospitalization and as a transitional stage in the restoration to community living. Their overall goals are: To prevent rehospitalization; to improve community adjustment; and to reduce the stigmatization of former mental patients. Increased self-understanding, improved interpersonal relationships, and the acquisition of new skills which will help a person cope with the pressures of the external and internal environment are emphasized with individual clients. In day treatment programs the se goals are operationalized primarily through the modalities of a the rapeutic milieu (Gross, 1971; and Glaser, 1969) and structured group activities (Glasscote, 1969; Meltzoff and Blumenthal, 1966). Glaser (1969) maintains that the concepts of a therapeutic community and of continual exposure to a number of groups form a unique program design.

A wide range of treatment techniques are reported in the literature on day treatment (Meltzoff and Blumenthal, 1966). Some examples are: Supportive counseling, directive counseling, role playing, environmental manipulation, and behavioral procedures such 
as extinction, positive reinforcement, and desensitization. These may occur in the context of a group. A more comprehensive viewpoint implies that day treatment can be implemented in conjunction with other social, vocational, and rehabilitation services in the community.

The phrase "in the community" is important when the location of a day treatment program is considered. Even though day treatment is an alternative to institutionalization, Glasscote (1969), in a survey of the available partial hospitalization and day treatment programs, found that all but sixteen of 139 programs were attached to an institution, either a hospital or a community mental health center. In fact, the concept of a community-based program has not been realized. Further, in a study of one community mental health center near Denver, Colorado (Glasscote, 1969), it was concluded that the rate of attendance at a day treatment center depended upon the distance a. . program client must travel from home. Thus, location is a key concept because it relates both to community care and to individual attendance.

Glasscote (1969) and Glaser (1969) separately report that twenty to forty individuals drawn from an active caseload of approximately fifty person may optimally attend a day treatment program. Economics and acceptance by the community have received little attention in the literature. Day treatment programs are considered 
less expensive than in-patient hospital care (Meltzoff and Blumenthal, 1966; Glaser, 1969). Glasscote (1969) also states that the importance of a day treatment program is still unrecognized by mental health professionals, the public, and consumers.

Lastly, there has been some reporting on the effectiveness of day treatment programs. Glasscote (1969) summarizes the research on the question of hospital-based treatment versus community-based treatment.

... There is substantial evidence that most of the persons traditionally admitted to twentyfour hour hospitalization can be successfully treated on day status. (Glasscote, 1969, p. 15)

One study of a day treatment center in a veterans hospital in Brooklyn, New York, revealed that the program was successful in maintaining individuals in the community. Day treatment clients generally improved in areas such as community adjustment and attitudes towards self, family, and independent living. However, there was little reported success in changing interpersonal relationships or in improving motivation for new achievements (Glasscote, 1969).

The concept of a day treatment program is generally a feasible one. Day treatment has the capacity to serve a large number of clients in their community. It can contain a wide variety of treatment activities so that the individual needs of clients at different levels of functioning may be met. Like other programs, day treat- 
ment encourages socialization, support, and behavioral change. Furthermore, a day treatment program does not remove a client from the natural environment in which the person lives, but offers services to the client and his or her significant others in that environment. A final advantage of a day treatment program is that it is a program model which has the potential to be used in the development of mental health resources within the community rather than within a hospital or other type of institution.

This program model has several disadvantages. First, there is a danger that the day treatment program might become merely a social center or community center. The balance between a supportive, nurturing atmosphere and a challenging atmosphere which increases the likelihood of individual changes is a balance that is difficult to maintain. Secondly, the program is restricted to those clients who have an established residence, who will travel from home to the center, and who will attend regularly. Finally, a major drawback is the costliness of implementing and operating a day treatment program, despite claims that it is less expensive than hospitalization. A day treatment program is a feasible model for Northwest Portland. Its size, location, and cost can be scaled to match the resources supplied by Zion Lutheran Church and the rest of the community. According to the Needs Assessment, the day treatment concept is well known, popular, and would be supported by the 
community of Northwest Portland.

Volunteer Programs

Volunteer programs have been attempted in a variety of settings among which are the following: A day treatment center (Minor, 1975); a mental health center (Katkin, 1975); and two followup programs from mental hospitals (Weinman, 1974; Watson, 1975). The function of these volunteers is generally adapted to the treatment philosophy of the agency which recruits them. For example, the day treatment center uses a self-actualizing approach which requires an individual treatment plan and individual schedules to fit specific needs. Hence, volunteers are used as additional personnel to carry out treatment plans. (Minor, 1975).

Generally, volunteers are placed in significant roles within an agency either as case aides (Hayler, 1975) or as therapists (Katkin, 1975). A key appears to be the extent of training and supervision. In most programs emphasis is placed on initial and on-going training (Hayler, 1975; Weinman, 1974). This is especially true in situations in which staff time could not be available for extensive supervision (Katkin, 1975). In the case of one program that failed, it appears that lack of training was the problem (Watson, 1975). From the literature it does appear that well-trained volunteers are a good supplement to program staff. 
A volunteer program which is not linked to an established service would not be reliable. In order to assure long-term commitment of volunteers to a program, availability of materials and equipment, as well as professional support, would be necessary. Feasibility of a volunteer program is dependent on the program in which the volunteers are used, therefore.

A volunteer program could be feasible in Northwest Portland. Such a program is adaptable to many locations and a variety of sizes. Provided that volunteers were recruited by an ongoing program, their activities could be an inexpensive part of that program. And, as indicated by the Needs Assessment, volunteers would be a very acceptable mode of service to clients and service providers in the area. 


\section{CHAPTER V}

\section{A PROPOSAL FOR A DEINSTITUTIONALIZATION PROGRAM}

\section{Introduction}

The purpose of this chapter is to propose a program which best fits the needs of post-hospitalized community residents in Northwest Portland and the resources of Zion Lutheran Church. Consideration is given here to the results of the literature search, the needs assessment, and the program feasibility chapters of this project. Through the process of developing the previous chapters the researchers concluded that the most feasible type of program is one. which is based on the structure of day treatment and the principles of group work. However, the proposed program is more socially oriented than a traditional day treatment program. This program focuses upon the social functioning of the former patients in the community and, in turn, the community's responsibility to provide suitable roles for the ex-patient. A daytreatment program, on the other hand, focuses on the psychological functioning of the individual. The special, yet narrower, emphasis of this proposal together with its smaller size makes it different from day treatment. It includes 
many of the training opportunities and rehabilitative and support services which the Needs Assessment showed are useful to ex-mental patients in Northwest Portland. For purposes of this chapter the program outlined below will be called a "deinstitutionalization program."

The authors make this proposal based on certain values and assumptions. A primary value is that each person has a right to reach his/her full potential and to have the means by which he/she may reach that potential. The researchers, thus, espouse a "high expectation" approach to the ex-mental patient. As outlined in the section on halfway houses in Chapter IV, this approach asserts that ex-patients can learn roles that will enable them to be contributing members of the community. It is a conclusion, based on findings of studies cited in the literature search, that long-term institutionalization results in dependent, passive behavior among ex-patients. Thus, whatever one's definition of mental illness, the process of deinstitutionalization involves changing the concepts that ex-patients have concerning their societal roles. For patients to adjust to community life, they have to move from a dependent, passive patient role to an independent, assertive role. Implicit in the concept of role change is another conclusion again derived from the literature search. It is that there is a distinction between a patient's community adjustment and his/her risk of recidivism. In most studies 
there were no significant factors related to recidivism. On the contrary, several factors were related to community adjustment. Thus, it is felt that a manageable program with measurable outcomes should focus on community adjustment.

"Community adjustment" in this program proposal refers to an individual's behavior. Expectations of behavior may be instrumental, relating to the knowledge and skills necessary to carry out tasks. They may also be expressive, relating to attitudes and values necessary to perform tasks. If one behaves in response to the se expectations which are determined according to what is acceptable to the community at large, then one is said to be adjusted. The result is community adjustment, or behavior which is functional for the individual as well as acceptable to community norms. Therefore, a role change by the ex-patient is only half of the task. The community norms themselves which support a marginal role for the person who has been released from a mental hospital must also change. As indicated, a "high expectation" program such as this one proposes to be, does not support marginal roles, but challenges expatients to reach their full potential. The concepts of individual change and social change are applied in the design of the program. This proposal, not only stands as a role model for the community, but also attempts to influence more directly the expressive and instrumental expectations the community has regarding ex-patients. 
The ex-patient's adjustment to community norms is not sufficient.

The community must also adjust to the ex-patient.

\section{Program Description}

The deinstitutionalization program has two components. One is a center which offers limited rehabilitation and support services and training opportunities by means of a daily schedule of group sessions and informal socialization. It operates approximately four hours per day for a five-day week. This format, derived from day treatment, is adaptable to many levels of social functioning among clients. A central location within Northwest Portland or within walking distance of several boarding homes is an ideal location for the center. If another location is chosen due to economic constraints or the availability of commercial real estate, the location must be accessible by public transportation. The second component of the deinstitutionalization program. consists of recreational activities which are planned and implemented within boarding homes and residential hotels. For example, a volunteer group worker will form recreational groups among residents after a service contract has been negotiated between owner-managers and program staff. The recreational activities will take place in the residential facility unless field trips are arranged. Through planning activities, buying tickets, securing transportation, and participating in recreation, a number of 
skills related to the use of leisure time will be learned. It is a cooperative effort between owner-managers of residential facilities and program staff. The responsibility for initiating this component for the program rests with the program staff. However, the ongoing operation of the recreational activities is a joint effort of owner-managers, program staff, and volunteers.

The first component, a center, is a small program which has the capacity to serve twenty-five or thirty clients. The recreational component is larger. It will.serve ex-psychiatric patients who reside in boarding homes and residential hotels, although other residents will also be served. It is estimated that approximately ten to twenty residents of six or eight different facilities may participate in recreational activities.

\section{Problem Definition}

This project came to the attention of the authors through Zion Lutheran Church. The pastor and the social services committee had been aware of a number of their church members who were expatients of mental institutions and residents of the general Northwest area of Portland. As described by the church, these ex-patients did not participate in community activities, lived alone, had few friends, and were without sufficient community services. At that time, the church suggested that a residence organized and maintained by Zion 
might relieve the problem.

A Needs Assessment supported the observations of the church but only minimally supported the development of another residential facility in Northwest Portland. Thus the authors' concept of a useful program has changed as the study has progressed. The Needs Assessment revealed the following conditions: There is a need for more services and for better residences for ex-mental patients in Northwest Portland. Ex-patients do lack support systems. They do not generally reside with their families. There are few community facilities which deal specifically with their needs. Lastly, ex-patients, themselves, are looking for social activities. Therefore, the problem as defined by Zion Lutheran Church has been confirmed by the research:

1. There are a number of post-hospitalized community residents living in Northwest Portland who are living apart from their families and who lack structure and meaning in their lives.

2. These individuals are without sufficient services.

\section{Goals}

The goals of the proposed program are to improve the community adjustment of post-hospitalized community residents in the direction of:

1. An increase in personal satisfaction; 
2. an improvement in social performance; and

3. an improvement in living conditions within boarding homes and residential hotels in the Northwest area of Portland.

\section{Objectives}

In relationship to the goals, the following outcomes are objectives of the program:

1. Clients will articulate satisfaction with themselves and with their social performance within the program and outside of it.

2. Clients will use leisure time in such a way that their time is structured, their boredom decreased, and their enjoyment increased.

3. Clients will communicate with others in their environment in a socially acceptable manner.

4. Clients will become better consumers of goods and services.

5. Clients will assess their employment skills.

6. Recreational activities will be available to residents of boarding homes and residential hotels.

7. The staff of the program will establish a working relationship with owner-managers of boarding homes and residential hotels.

Strategies

The strategies proposed relate directly to at least one, and 
sometimes two, program goals. In the program's first component, the center, strategies involve both group work and education. The groups which make up the center's program are educational, problemsolving, and activity groups. The first type, educational groups, emphasize either social skills training or the acquisition of information. In these groups assertion techniques, communication techniques, or short informative courses might be employed. Topics for the short courses might be: The use of psychotropic medication, gaining access to welfare or SSI services, becoming a better consumer, and developing a hobby. The second type of group emphasizes attitudes and values of independent community living. A job-readiness group and a goal-setting or problem-solving group are proposed. Finally, activity groups are the third type, and the se would use such mediums as art and crafts and music as means to increase social participation. The goal of improved social performance is the basis of the proposal of these groups. In addition, the goal of increased personal satisfaction is likely to occur, particularly through the problem-solving approach.

In the second component of the deinstitutionalization program, the strategies are twofold. First, recreational activities will be organized within boarding homes and residential hotels. This would include developing activities within the house or hotel as well as attending events in the community. Secondly, a service contract 
between owner-managers and program staff will be negotiated. The owner-managers will be asked to enter a service agreement to provide space, staff, and some supplies which are necessary to conduct the program. The provision of recreational activities in collaboration with owner-managers is a beginning step toward meeting the third goal which is improvement of living conditions within these facilities. Through a working relationship between owner-managers and the program staff, perhaps a consultative one, other improvements in living conditions may develop. For example, residents may be provided with an opportunity to earn extra money or given a voice in such areas as planning menus, selection of roommates, or writing house rules.

\section{Tasks}

Program tasks are activities that must be performed in order for the program to operate. One step of implementation of the program is that a consensus must be reached among program staff and clients about the terminology used in the statement of goals and objectives. This is a beginning task. Additional tasks include: Screening of program clientele, record-keeping, and staff communication. A screening process is important. First, the priority of the program is to serve the ex-institutionalized population. Screening, secondly, ensures that persons who have severe patterns 
of destructive or anti-social behavior are not included in the program. The program is not designed to handle such behavior. The screening procedure may be as follows: Each individual will be screened at entry; the combination of services which best fit his or her needs will be developed; and these program activities will be scheduled. A contract for services is thus formulated between program staff and client. Should the individual be in need of services beyond the scope of the program, the person will be referred to appropriate community agencies as a part of the screening process. This implies that the use of the center will be monitered by program staff. The next task is record-keeping. Records of activities will be kept for purposes of accountability and program evaluation. It is essential that the program be evaluated to ensure that it is meeting its objectives. The goals and objectives of this proposal are formulated in a manner which will facilitate the evaluation process. A third task is the routine scheduling of staff meetings and in-service training.

\section{Linkages}

In order for a neighborhood mental health program to survive, it must establish and maintain linkages with other community agencies. Initially, the priorities are to establish ties with three agencies: 1) Boarding homes and residential hotels, 2) the county 
mental health clinic, and 3) the local public welfare branch office. Linkages with these service delivery systems are important because: i) Contact with boarding homes and residential hotels is an essential part of the program, and 2) through all of them a referral mechanism by which clients enter the program can be developed.

\section{Resources}

In anticipation that a budget will be developed by those who fund the proposed program, the authors have attempted to identify minimal resources that are necessary for implementation of the program. Physical resources which will be needed include: A physical plant containing at least three rooms and a bathroom, living room furniture, office equipment and supplies, and arts and crafts supplies. In addition, a telephone and utilities must be provided. The personnel which are necessary include: One fulltime, salaried mental health professional; three half-time, salaried paraprofessionals; one half-time, salaried secretary; a psychiatrist as a consultant when needed; and five volunteers to work in the recreational component of the program.

\section{Conclusion}

Considerable research, time, and energy has preceded the writing of this brief proposal. The authors feel that the proposal provides a good foundation for a manageable program. The 
deinstitutionalization program would benefit the Northwest area of Portland. It would address problems faced by post-hospital residents in that area.

To that end, the proposal only outlines a program. However, the program proposal is specific enough to give its future developers a clear sense of direction. As outlined, the program would be relatively small. But with the sense of direction it provides, the proposal could be expanded in a number of ways. The authors suggest two. First, with added staff and funding, clients could be asked to assume positions within the program, such as visitors to clients who cannot come to the center, or as hosts and receptionists at the center. Such positions would necessarily be compensated. If these positions could be available during the individual screening process, they would provide status to those who had made progress, and challenges to those who had not. Second, the authors see a great need to extend the program in the area of community education. If community attitudes toward former mental patients are to change, an aftercare program must confront those attitudes rather than simply accept them.

The plan is also general enough to allow Zion Lutheran Church, who commissioned its development, flexibility for additional input and for adaptation to particular circumstances. Budgetary concerns have not been itemized here because availability of funding 
sources to the Church will effect program development. Much can be done with this proposal, but its implementation will depend on the strong motivation of a good number of people who will wish to see that it becomes a reality. 


\section{APPENDIX A}

\section{A SELECTED BIBLIOGRAPHY OF POST-HOSPITAL FOLLOW-UP STUDIES OF MENTAL PATIENTS}

Angrist, Shirley S.; Lefton, Mark; Dinitz, Simon; and Pasamanick, Benjamin. Women After Treatment, New York: AppletonCentury-Crofts, 1968

Anthony, William A. and Buell, Gregory J. "Predicting Psychiatric Rehabilitation Outcome Using Demographic Characteristics: A Replication," Journal of Counseling Psychology, September 1974, Vol. 21, no. 5, 421-422.

Arthur, Gilbert; Ellsworth, Robert B.; and Kroeker, Duane. "Readmission of Released Mental Patients: A Research . Study," Social Work, October 1968, Vol. 13, no. 4, 78-84.

Bachrach, Leona L. "A Note on Some Recent Studies of Released Mental Hospital Patients in the Community, " American Journal of Psychiatry, January 1976, Vol. 133, no. 1, 73-75.

Blackman, Sheldon, and Goldstein, Kenneth. "Some Aspects of a Theory of Community Mental Health," Community Mental Health Journal, February 1968, Vol. 4, no. 1, 85-90.

Bloom, Bernard L.; Long, Edward M. ; and Goldberg, Herbert. "Factors Associated with Accuracy of Prediction of Posthospital Adjustment, " Journal of Abnormal Psychology, October 1970, Vol. 76, no. 2, 243-249.

Buell, Gregory J. and Anthony, William A. "Demographic Characteristics as Predictors of Recidivism and Post-Hospital Employment, " Journal of Counseling Psychology, July 1973, Vol, 20, $361-365$.

Davis, Ann E.; Dinitz, Simon; and Pasamanick, Benjamin. "The Prevention of Hospitalization in Schizophrenia, "American Journal of Orthopsychiatry, April 1972, Vol. 42, No. 3, 375-388. 
Ellsworth, R. B.; Foster, L.; Childes, B.; Arthur, G.; and Kroeker, D. "Hospital and Community Adjustment as Perceived by Psychiatric Patients, their Families, and Staff," Journal of Consulting and Clinical Psychology, October 1968, Vol. 32, No. 5, Part II, 1-41.

Erickson, Richard C. and Paige, Albert B. "Fallacies in Using Length of Stay and Return Rates as Measures of Success," Hospital and Community Psychiatry, August 1973, Vol. 24, no. $8,559-561$.

Fairweather, G.W.; Sanders, D.H.; Cressler, D. L. ; and Maynard, H. Community Life for the Mentally IIl, Chicago, Ill. : Aldine, 1969.

Fontana, Alan, and Davis, Barbara. "Assessing Treatment Outcome: Adjustment to the Community, "Journal of Nervous and Mental Diseases, October 1975, Vol. 161, No. 4, 221-230.

Freeman, Howard Edgar and Simmons, Ozzie G. The Mental Patient Comes Home, New York: Wiley and Sons, 1963.

Graham, John R., et al. "Measuring Behavior and Adjustment in the Community: A Factor Analytic Study of the Katz Adjustment Scale, " Journal of Community Psychology, January 1973, Vol. 1, no. $1,48-53$.

Gregory, Caesar C., and Downie, N. M. "Prognostic Study of Patients Who Left, Returned, and Stayed in a Psychiatric Hospital," Journal of Counseling_Psychology, May 1968, Vol. 15, no. $3,232-236$.

Griffiths, R. D. P. "A Standardized Assessment of the Work Behavior of Psychiatric Patients, "British Journal of Psychiatry, October 1973, Vol. 123, no. 575, 403-408.

Hall, Julian C.; Smith, Kathleen; and Shimkunas, Algimantras. "Employment Problems of Schizophrenic Patients," American Journal of Psychiatry, November 1966, Vol. 123, no. 5, 536540.

Heckel, Robert V.; Peery, Charles; and Reeves, P.G. The Discharged Mental Patient: A Five Year Statistical Survey, Columbia, South Carolina: University of South Carolina Press, 1973. 
Joint Commission on Mental Illness and Health, Action for Mental Health, New York: Basic Books, Inc., 1961.

Jones, Maxwell. "Community Care for Chronic Mental Patients: The Need for Reassessment," Hospital and Community Psychiatry, February 1975, Vol. 26, no. 2, 94-98.

Kirk, Stuart A., and Therrien, Mark E. "Community Mental Health Myths and the Fate of Former Hospitalized Patients," Psychiatry, August 1975, Vol. 38, no. 3, 209-217.

Koltuv, Myron, and Neff, Walters. "The Comprehensive Rehabilitation Center: Its Role and Realm in Psychiatric Rehabilitation," Community Mental Health Journal, June 1968, Vol. 4, no. 3, $251-259$.

Kraft, Alan; Benner, Paul; Truitt, Ethel; and Morton, Duke W. "The Psychiatric Care System's Silent Majority," American Journal of Psychiatry, July 1971, Vol. 128, no. 1, 26-30.

Kunce, Joseph T. and Worley, Bert. "Simplified Prediction of Occupational Adjustment of Distressed Clients," Journal of Counseling Psychology, July 1970, Vol. 17, no. 4, 326-330.

Lipsitt, Don R. "Institutional Dependency: A Rehabilitation Problem" in Greenblatt, Milton; Levinson, Daniel J.; Klerman, Gerald L.; and Ewalt, Jack R., eds., Mental Patients in Transition, Springfield, Illinois: Charles C. Thomas, Publisher, 1961, $34-45$.

Lorei, Theordore W. "Prediction of Community Stay and Employment for Released Psychiatric Patients," Journal of Consulting Psychology, August 1967, Vol. 31, no. 4, 349-357.

Lorei, Theordore W., and Gurel, Lee. "Comparis on of Ex-Mental Patient Employment Information Obtained by Mail and by Interview, "Journal of Counseling Psychology, September 1967, Vol. 14, no. 5, 458-461.

Lorei, Theodore W., and Gurel, Lee. "Demographic Characteristics as Predictors of Posthospital Employment and Readmission," Journal of Consulting and Clinical Psychology, June 1973, Vol. 40 , no. $3,426-430$. 
Lorei, Theordore W., and Gurel, Lee. "Use of a Biographical Inventory to Predict Schizophrenics' Posthospital Employment and Readmission, " Journal of Consulting and Clinical Psychology, April 1972, Vol. 32, no. 2, 238-243.

Lyon, Keith E., and Zucker, Robert A. "Environmental Supports and Post-Hospital Adjustment," Journal of Clinical Psychology, October 1974, Vol. 30, no. 4, 460-465.

Mannino, Fortune V., and Shore, Milton F. "Demonstrating Effectiveness in an Aftercare Program," Social Work, May 1974, Vol. 19, no: 3, 351-354.

Mannino, Fortune V., and Shore, Milton F. "Family Structure, Aftercare, and Posthospital Adjustment," American Journal of Orthopsychiatry, January 1974, Vol. 44, no. 1, 76-85.

Measey, Lawrence G., and Smith, Howard. "Patterns of New Chronicity in a Mental Hospital, " British Journal of Psychiatry, September 1973, Vol. 123, no. 574, 349-351.

Michaux, William W.; Katz, Martin M. ; Kurland, Albert A. ; and Gansereit, Kathleen H. The First Year Out: Mental Patients after Hospitalization, Baltimore, Maryland: The John Hopkins Press, 1969.

Miller, Dorothy. "Retrospective Analysis of Posthospital Mental Patients' Worlds," Journal of Health and Social Behavior, June 1967, Vol. 8, no. 1, 136-140.

Olshansky, S.; Grob, S. ; and Ekdahl, M. "Survey of Employment Experiences of Patients Discharged from Three State Mental Hospitals during the Period 1951-1953," Mental Hygiene, October 1960, Vol. 44, no. 4, 510-521.

Pasamanick, Benjamin; Scarpitti, Frank; and Dinitz, Simon. Schizophrenics in the Community, New York: AppletonCentury-Crofts, 1967.

Paul, Gordon L. "Chronic Mental Patient: Current Status--Future Directions," Psychological Bulletin, February 1969, Vol. 71, no. 2, 81-94. 
Purvis, S. A., and Miskimins, R. W. "Effects of Community FollowUp on Posthospital Adjustment of Psychiatric Patients, " Community Mental Health Journal, October 1970, Vol. 6, no. 5, 374-382.

Rosen, Bernard; Klein, Donald F.; and Gittleman-Klein, Rachel. "The Prediction of Rehospitalization: The Relationship between Age of First Psychiatric Treatment Contact, Marital Staus, and Premorbid Asocial Adjustment," Journal of Nervous and Mental Disease, January 1971, Vol. 152, no. 1, 17-22.

Rosenblatt, A., and Mayer, J.E. "The Recidivism of Mental Patients: A Review of Past Studies," American Journal of Orthopsychiatry, October 1974, Vol. 44, no. 5, 697-706.

Rutledge, Louis and Binner, Paul. "Readmissions to a Community Mental Health Center," Community Mental Health Journal, April 1970, Vol. 6, no. 2, 136-143.

Simmons, Ozzie G. Work and Mental Illness, New York: John Wiley and Sons, 1965.

Sinkett, E. Robert; Stimpert, Warren E.; and Straight, Elmer. "A Five Year Follow-Up Study of Psychiatric Patients," American Journal of Orthopsychiatry, April 1965, Vol. 35, no. 3, 573-580.

Spiegel, Dan and Younger, Jenny B. "Life Outside the Hospital," Mental Hygiene, Spring 1972, Vol. 56, no. 2, 9-20.

Stewart, A.; Selkirk, Sheena A.; and Sydiaha, D. "Patterns of Adjustment of Discharged Psychiatric Patients, " Community Mental Health Journal, August 1969, Vol. 5, no. 4, 314-319.

Walker, L.G.; Adamson, F.A.; Alexander, D. A.; Stoffelmayr, B.E. "A Negative Correlation Between Improved Production in Psychiatric Rehabilitation and Social Behavior Outside," British Journal of Psychiatry, October 1973, Vol. 123, no. 575, 409-412.

Wessler, Richard L:, and Iven, Donna. "Social Characteristics of Patients Redadmitted to a Community Mental Health Center," Community Mental Health Journal, February 1970, Vol. 6, no. $1,69-74$. 
White, W.C., Jr.; McAdoo, William George; and Phillips, Leslie. "Social Competence and Outcome of Hospitalization: A Preliminary Report," Journal of Health and Social Behavior, September 1974, Vol. 15, no. 3, 261-266.

Wolkon, George H. "Characteristics of Clients and Continuity of Care in the Community," Community Mental Health Journal, June 1970, Vol. 6, no.13, 215-221. 
APPENDIX B

\section{A SELECTED BIBLIOGRAPHY OF COMMUNITY-BASED AFTERCARE PROGRAMS}

\section{Halfway Houses}

Budson, Richard L. "Legal Dimensions of the Psychiatric Halfway House," Community Mental Health Journal, Fall 1975, Vol.11, no. $3,316-324$.

Easton, Karl. "Some Psychodynamic Considerations in the Program Development of Boerum Hill: A Psychiatric Halfway House," Community Mental Health Journal, Winter 1974, Vol. 10, no. $4,395-401$.

Gill, W. S. "San Antonio's Halfway House," Hospital and Community Psychiatry, September 1967, Vol. 18, no. 9, 281.

Goveia, L.H. "Quarters: A Case for Community Action," Community Mental Health Journal, Winter 1965, Vol. 1, no. 4, 385386.

Gumrukcu, Patricia. "The Efficiency of a Psychiatric Halfway House: A Three-Year Study of a Therapeutic Residence," Sociological Quarterly, 1968, Vol. 9, no. 3, 374-386.

Grumrukcu, P., and Mikels, E. "Combating Post-Hospital Bends: Patterns of Success and Failure in a Psychiatric Halfway House," Mental Hygiene, April 1965, Vol. 49, no. 2, 244-249.

Hersen, Michel. "Independent Living as a Threat to the Institutionalized Mental Patient," Journal of Clinical Psychology, July 1969, Vol. 25, no. 3, 316-318.

Huessy, Hans R. "Beyond the Halfway House;" International Journal of Social Psychiatry, 1969a, Vol. 15, no. 3, 235-239. 
Huessy, Hans R. "Satellite Halfway Houses in Vermont," Hospital and Community Psychiatry, May 1969, Vol. 20, no. 5, 147-149.

Jansen, Elly. "The Role of the Halfway House in Community Mental Health Programs in the United Kingdom and America," American Journal of Psychiatry, April 1970, Vol. 126, no. 10, 1498-1504.

Landy, D., and Greenblatt, M. Halfway House - A Sociocultural and Clinical Study of Rutland Corner House, Washington, D. C. : Vocation Rehabilitation Administration, Department of H.E.W. 1965.

Mikels, Elaine and Gumrukcu, Patricia. "Conrad House - Bridge to Reality," Rehabilitation Record, July-August 1963, Vol. 4, no. $4,24-27$.

Mikels, Elaine and Gumrukcu, Patricia. "For the Former Mental Patient, A Therapeutic Community Hostel, " Journal of Rehabilitation, May-June 1963, Vol. 29, no. 3, 20-21.

Raush, Harold L., and Raush, Charlotte L. The Halfway House Movement: A Search for Sanity, New York: Appleton-CenturyCrofts, 1968.

Reik, I. "The Halfway House: The Role of Laymen's Organizations in the Rehabilitation of the Mentally Ill," Mental Hygiene, October 1953, Vol. 37, no. 4, 615-618.

Richmond, Charles. "Programs for Discharged Patients - Halfway House and Day Hospital Complement Each Other, "Hospital and Community Psychiatry, March 1968, Vol. 19, no. 3, 78-79.

Richmond, Charles. "Transitional Housing" in Lamb, H. R., Heath, D. , and Downing, J., eds., Handbook of Community Mental Health Practice, San Francisco: Jossey-Bass, Inc., 1969, $145-174$.

Rog, Dennis J., and Raush, Harold L. "The Psychiatric Halfway House: How is it Measuring Up?" Community Mental Health Journal, Summer 1975, Vol. 11, no. 2, 155-162. 
Rothwell, Naomi D., and Doniger, Joan M. "Halfway House and Mental Hospital - Some Comparisons, "Psychiatry, August 1963, Vol. 26, no. 3, 281-288.

Rothwell, Naomi D., and Doniger, Joan M. The Psychiatric Halfway House, Springfield, Illinois: Charles C. Thomas, 1966.

Sharp, G. "A Perspective on the Function of the Psychiatric Halfway House," Mental Hygiene, October 1964, Vol. 48, no. 4, 552-557.

Shearer, R. M. "The Structure and Philosophy of Georgia's Halfway Houses," Hospital and Community Psychiatry, April 1969, Vol. 20, no. 4, 115-118.

Wechsler, Henry. "Halfway Houses for Former Mental Patients: A Survey," Journal of Social Issues, 1960, Vol. 16, no. 2, $20-26$.

Weinman, Bernard; Sanders, Richard; Kleiner, Robert; Wilson, Stephen. "Community Based Treatment of the Chronic Psychotic, " Community Mental Health Journal, 1970, Vol. 6, no. $1,13-21$.

Weiss, Bernard; Roberts, Pearl, and Wolford, Jack. "The Uninvolved: A Study of Services for Former Mental Patients, " International Journal of Social Psychiatry, 1969, Vol. 15, no. $3,223-229$.

Wilder, J.F.; Kessel, M.; and Caulfield, S.C. "Follow-up of a High Expectation Halfway House," American Journal of Psychiatry, February 1968, Vol. 124, no. 2, 1085-1091.

\section{Cooperative Apartments}

Chien, Ching-Piao and Cole, Jonathan O. "Landlord-Supervised Cooperative Apartments: A New Modality for CommunityBased Treatment," American Journal of Psychiatry, February 1973, Vol. 130, no. 2, 156-159.

Hodgman, E. and Stein, E. "Cooperative Apartment;" Community Mental Health Journal, Winter 1966, Vol. 2, no. 4, 347-352. 
Kresky, Marilyn; Maeda, Edith M. ; and Rothwell, Naomi D. "The Apartment Program: A Community Living Option for Halfway House Residents," Hospital and Community Psychiatry, March 1976, Vol. 27, no. 3, 153-154.

Richmond, Charles. "Transitional Housing" in Lamb. H. R., Heath, D. , Downing, J., eds., Handbook of Community Mental Health Practice, San Francisco: Jossey-Bass, Inc., 1969, $145-174$.

Foster Homes and Ex-patient Clubs

Cunningham, Murray K.; Botivinik, William; Dolson, James; and Weickert, Andrew. "Community Placement of Released Mental Patient," Social Work, 1969, Vol. 14, no. 1, 54-61.

Murphy, Henry B.; Engelsmann, Frank; and Tcheng-Laroche, Francoise. "The Influence of Fosterhome Care on Psychiatric Patients," Archives of General Psychiatry, February 1976, Vol. 33, no. 2, 179-183.

Wechsler, Henry. "The Ex-Patient Organization: A. Survey," Journal of Social Issues, 1960, Vol. 16, no. 2, 47-53.

Wechsler, Henry. "The Ex-Patient Club" in Greenblatt, M.; Levinson, D.J.; and Klerman, G.L., editors, Mental Patients in Transition, Springfield, Illinois: Charles C. Thomas, 1961, 104-111.

\section{Day Treatment Programs}

Glaser, Frederick B. "Our Place: Design for a Day Program," American Journal of Orthopsychiatry, October 1969, Vol. 39, no. 5, 827-841.

Glasscote, Raymond M. ; Kraft, Alan M. ; Glassman, Sidney M. ; and Jepson, William W. Partial Hospitalization for the Mentally Ill, Washington, D. C.: The Joint Information Service, 1969.

Gross, Ruth B. "A Conceptual Outline for Day Treatment Center Practice," Comprehensive Psychiatry, September 1971 , Vol. 12, no. 5, 437-449. 
Meltzoff, Julian; and Blumenthal, Richard L. The Day Treatment Center: Principles, Application, and Evaluation. Springfield, Illinois: Charles C. Thomas, Publisher, 1966.

Siroka, Ellen K. "The Non-Residential Therapeutic Community as a Treatment Modality," Dissertation Abstracts International, December 1974, Vol. 35, no. 6-B, 3036-3037.

Volunteer Programs

Hayler, Laurel S. "Administrative Considerations in Developing a Volunteer Program, " Hospital and Community Psychiatry, March 1975, Vol. 26, no. 3, 143-145.

Katkin, Steven; Ginsburg, Marshall; Rifkin, Marilyn; and Scott, James. "Effectiveness of Female Volunteers in the Treatment of Outpatients, " Journal of Counseling_Psychology, 1971, Vol. 18, no. 2, 97-100.

Katkin, Steven; Zimmerman, Virginia; Rosenthal, Jonathan; and Ginsberg, Marshall. "Using Volunteer Therapists to Reduce Hospital Readmissions, " Hospital and Community Psychiatry, March 1975, Vol. 26, no. 3, 151-153.

Minor, Kirk, and Thompson, Pat. "Development and Evaluation of a Training Program for Volunteers Working in Day Treatment," Hospital and Community Psychiatry, March 1975, Vol. 26, no. 3, 154-156.

Watson, Charles G.; Fulton, John R.; Gurel, Lee. "Project Anchor: A Study of an Unsuccessful Volunteer Program to Help Former Patients, "Hospital and Community Psychiatry, March 1975, Vol. 26, no. 3, 146-151.

Weinman, Bernard; Kleiner, Robert; Yu, Jin H. ; and Tillson, Vick. "Social Treatment of the Chronic Psychotic Patient in the Community," Journal of Community Psychology, October 1974, Vol. 2, no. 4, 258-265. 


\section{APPENDIX C}

\section{RESEARCH INSTRUMENTS}

\section{SERVICE PROVIDER QUESTIONNAIRE - FORM 1}

\section{Group}

1. Does your organization serve adults over 21 who have been released from mental hospitals?

Yes No

A. Do any of these clients live in Northwest Portland?

$$
\text { Yes }
$$
No

B. If yes, how many did your organization serve last year?

2. Of those former mental patients that you have served in the last year what percentage have....
A. Drug or alcohol addiction?
B. Organic brain syndrome and retardation?
C. Physical illness that requires nursing care?

When answering the remaining questions, please exclude persons with drug or alcohol addiction, with organic syndrome and retardation, and physical illness that requires nursing care.

3. List the following residential settings in the order that they are most frequently used by this group. Please rank them 1 to 5 , with 1 meaning most frequently used. 
A. Boarding homes and residential hotels.

B. At home with relatives other than spouse.

C. At home with spouse.

D. Residential care facility.

E. Alone.

4. Would an additional residential facility, if provided, be used by the group mentioned above?

Yes No

5. On a scale of 1 to 4, please rate the following training opportunities. If you feel the training would be very much used by this group, choose 1; would be used some, choose 2; would be used very little, choose 3; and would not be used at all, choose 4 .

A. Daily living skills

1. Money management and shopping

2. Housekeeping

3. Personal appearance and habits

4. Use of public transportation

5. Use of leisure time

$\begin{array}{llll}1 & 2 & 3 & 4 \\ 1 & 2 & 3 & 4 \\ 1 & 2 & 3 & 4 \\ 1 & 2 & 3 & 4 \\ 1 & 2 & 2 & 4\end{array}$

B. Social skills - getting along with others $1124 \begin{array}{llll} & 2 & 4\end{array}$

C. Vocational Rehabilitation

D. Basic Education

E. Problem Solving Skills

$\begin{array}{llll}1 & 2 & 3 & 4\end{array}$

F. Other - Specify

$123 \quad 3 \quad 4$

1234

$1 \quad 2 \quad 3 \quad 4$


6. Please rate the following rehabilitative and support services. If you feel the rehabilitative or support service would be very much used choose 1; would be used some, choose 2; would be used very little, choose 3; and would not be used at all, choose 4.
A. Individual counseling
$\begin{array}{llll}1 & 2 & 3 & 4\end{array}$
B. Group counseling
C. Recreational activities
$\begin{array}{llll}1 & 2 & 3 & 4\end{array}$
D. Supervised group living
$\begin{array}{llll}1 & 2 & 3 & 4\end{array}$
E. Self-help groups
1234
F. Family or marriage counseling
$\begin{array}{llll}1 & 2 & 3 & 4\end{array}$
G. Clothes closet
123.4
H. Referrals to community agencies
1234
I. Use of trained volunteers
1234
J. Legal Aid
K. Psychiatric consultation
1. 234
$12 \cdot 34$
L. 24-hour availability of professional consultation
M. Other - Specify

$\begin{array}{llll}1 & 2 & 3 & 4\end{array}$

7. Would the following methods be 1 -excellent; 2 -good; 3 -fair; or 4 - poor means of offering the services that are most needed.
A. Day treatment program
B. Apartment co-op program
C. Foster homes
D. "Big brother/sister" program
E. Outpatient clinical services
$\begin{array}{llll}1 & 2 & 3 & 4\end{array}$
$\begin{array}{llll}1 & 2 & 3 & 4\end{array}$
$\begin{array}{llll}1 & 2 & 3 & 4\end{array}$
$\begin{array}{llll}1 & 2 & 3 & 4\end{array}$
F. Community service center
G. Sheltered workshop
$\begin{array}{llll}1 & 2 & 3 & 4\end{array}$
$\begin{array}{llll}1 & 2 & 3 & 4\end{array}$
H. On-the-job-training
$1 \quad 2 \quad 3 \quad 4$
I. A short-term residential facility

123.4
( 3 months)
J. A long-term residential facility
$\begin{array}{llll}1 & 2 & 3 & 4\end{array}$
K. Other - Specify
$\begin{array}{llll}1 & 2 & 3 & 4\end{array}$
$\begin{array}{llll}1 & 2 & 3 & 4\end{array}$

8. What would you do to help those who are making the transition from hospital to community? 


\section{CLIENT QUESTIONNAIRE - FORM 2}

1. Are you over 21 years old?

Yes

No

Do you live in Northwest Portland?

Yes

No

Have you ever been a patient in a mental hospital?

Yes No

Have you ever been diagnosed as having...
A. Drug or alcohol addiction?
Yes
No
B. Organic brain syndrome and retardation?
Yes
No
C. Physical illness that requires nursing care?
Yes No

2. Do you know other people who have been patients

in a mental hospital?

Yes No

If yes, how many?

What percentage have been diagnosed as having ...

A. Drug or alcohol addiction?

B. Organic brain syndrome and retardation?

C. Physical illness that requires nursing care? 
3. This is a list of places to live. Please rank them in the order that they are most frequently used by those you know who have been released from mental hospitals. Number them 1 to 5 , with 1 meaning most frequently used.

A. Boarding homes and residential hotels.

B. At home with relatives other than spouse.

C. At homw with spouse.

D. Residential care facility.

E. Alone.

4. Would those you know who have been released from mental hospitals use more places to live, if they were provided?

Yes No

5. On a scale of 1 to 4 , please rate the following training opportunities. If you feel the training would be very much used by those you know who have been released from mental hospitals, choose 1; would be used some, choose 2 ; would be used very little, choose 3; and would not be used at all, choose 4 .

A. Daily living skills

1. Money management and shopping

2. Housekeeping

3. Personal appearance and habits $\quad 1 \quad 2 \quad 304$

4. Use of public transportation $\quad 1 \quad 2 \quad 304$

5. Use of leisure time $\quad 1102034$

B. Social skills - getting along with others $1 \quad 2 \quad 344$.

$\begin{array}{lllll}\text { C. Vocational rehabilitation } & 1 & 2 & 3 & 4\end{array}$

D. Basic education $\quad \begin{array}{lllll}1 & 2 & 3 & 4\end{array}$

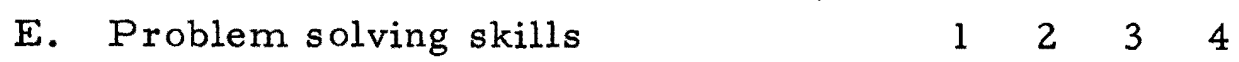

F. Other. Specify _ $\begin{array}{llll}1 & 2 & 3 & 4\end{array}$ 
6. Please rate the following rehabilitative and support services. If you feel the rehabilitative or support service would be very much used, choose 1; would be used some, choose 2; would be used very little, choose 3; and would not be used at all, choose 4 .
A. Individual counseling
$\begin{array}{llll}1 & 2 & 3 & 4\end{array}$
B. Group counseling
C. Recreational activities
$\begin{array}{llll}1 & 2 & 3 & 4\end{array}$
D. Supervised group living
$\begin{array}{llll}1 & 2 & 3 & 4\end{array}$
E. Self-help groups
F. Family or marriage counseling

$\begin{array}{llll}1 & 2 & 3 & 4\end{array}$
G. Clothes closet
H. Referrals to community agencies
$\begin{array}{llll}1 & 2 & 3 & 4\end{array}$
I. Use of trained volunteers
$\begin{array}{llll}1 & 2 & 3 & 4\end{array}$
$\begin{array}{llll}1 & 2 & 3 & 4\end{array}$
J. Legal Aid
$\begin{array}{llll}1 & 2 & 3 & 4\end{array}$
K. Psychiatric consultation
$\begin{array}{llll}1 & 2 & 3 & 4\end{array}$
L. 24-hour availability of professional
L. 24-hour availability of professional
consultation
M. Other. Specify

7. Would the following methods be 1 -excellent, 2 -good, 3-fair, or 4 - poor means of offering the services that are most needed? Please rate each one.
A. Day treatment program
B. Apartment co-op program
$\begin{array}{llll}1 & 2 & 3 & 4 \\ 1 & 2 & 3 & 4 \\ 1 & 2 & 3 & 4\end{array}$
C. Foster homes
D. "Big brother/sister" program
$\begin{array}{llll}1 & 2 & 3 & 4 \\ 1 & 2 & 3 & 4\end{array}$
E. Outpatient clinical services
$\begin{array}{llll}1 & 2 & 3 & 4\end{array}$
F. Community service center
G. Sheltered workshop
$\begin{array}{llll}1 & 2 & 3 & 4\end{array}$
H. On-the-job training
$\begin{array}{llll}1 & 2 & 3 & 4\end{array}$
I. A short-term residential facility
$\begin{array}{llll}1 & 2 & 3 & 4\end{array}$ ( 3 months)
K. Other. Specify
J. A long-term residential facility

$\begin{array}{llll}1 & 2 & 3 & 4 \\ 1 & 2 & 3 & 4 \\ 1 & 2 & 3 & 4\end{array}$

